\title{
Avaliação da percepção da conformidade de processos de contratação de soluções de Tecnologia da Informação com a Instrução Normativa no 4/2010 da SLTI
}

Diana Leite Nunes dos Santos e João Souza Neto

\section{Introdução}

Weil e Ross (2006) citam os investimentos e a priorização da Tecnologia da Informação (TI) entre as cinco decisões-chave a serem tratadas para se alcançar uma governança de TI eficaz. Essa decisão estratégica envolve determinar quanto gastar, em que gastar (o portefólio de investimentos de TI) e como alinhar as necessidades de diferentes partes interessadas com as prioridades estratégicas.

A questão sobre investimentos também tem destaque na norma ABNT NBR ISO/IEC 38500:2009 - referencial sobre governança corporativa de TI -, que elenca o princípio da aquisição entre os seis princípios que devem nortear a boa governança de TI, nos seguintes termos:

"As aquisições de TI são feitas por razões válidas, com base em análise apropriada e contínua, com tomada de decisão clara e transparente. Existe um equilíbrio apropriado entre benefícios, oportunidades, custos e riscos, de curto e longo prazo" (ABNT, 2009, p. 6). 
Grembergen e De Haes (2010) identificam 33 práticas, 12 estruturas, 11 processos e 10 mecanismos relacionais para governança corporativa de TI, e sua pesquisa mostra que o controle e reporte do orçamento de TI está entre os cinco elementos de maior efetividade para se alcançar o sucesso dessa governança.

Além do destaque encontrado em nível estratégico, esse assunto também é tratado nas esferas tática e operacional. Encontram-se referências na área de gestão de projetos, como no guia PMBOK 4.0 e na Metodologia de Gerenciamento de Projetos do Sistema de Administração dos Recursos de Infor mação e Informática (MGP-SISP), que trazem um capítulo exclusivo tratando da área de conhecimento "Aquisições"; e no framework COBIT 5, com as práticas APO06.03 Create and maintain budgets e BAI03.04 Procure solution components, e o processo APO10 Manage Suppliers.
No âmbito da administração pública federal (APF), as contratações de soluções de TI ganham importância e relevância ao se considerar o volume dos gastos em TI, que, em 2010, somaram cerca de $\mathrm{R} \$$ 12,5 bilhões, sendo que parte significativa desse orçamento se dirige para a contratação de serviços relacionados a software, conforme levantamento do Tribunal de Contas da União (TCU) (BRASIL, 2012a, p. 14).

Uma parcela tão significativa do orçamento público e a provável dependência direta ou indireta da TI para a execução de um orçamento que chega a R\$ 1,8 trilhão (BRASIL, 2010) trouxeram grande visibilidade e preocupação aos órgãos de controle como o TCU, o que pode ser observado no crescimento contínuo e acelerado da quantidade de acórdãos e decisões relacionados a contratações de TI, como mostra a Figura 1 (Cruz, 2011, p.25).

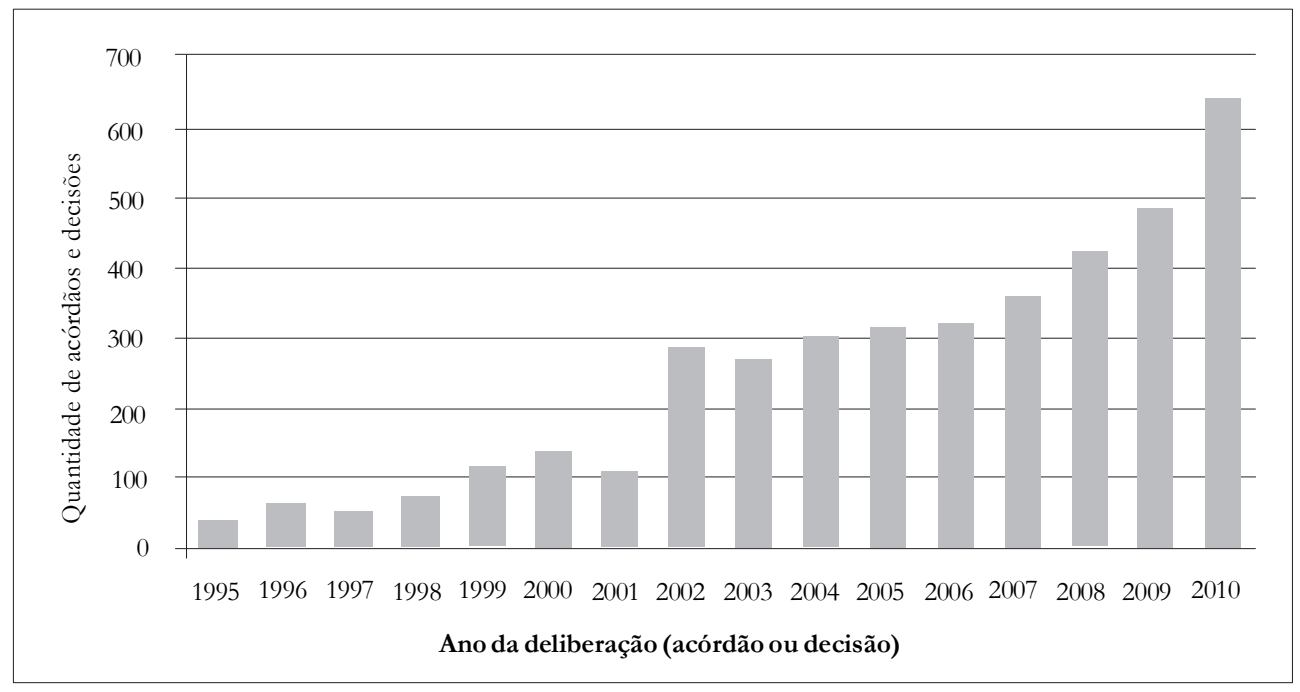

Fonte: Cruz, 2011.

Figura 1: Evolução das deliberações do TCU acerca de contratações de serviços de TI 
Em atendimento ao item 9.4 do Acórdão 786/2006-TCU-Plenário, a Secretaria de Logística e Tecnologia da Informação (SLTI) publicou a Instrução Normativa $n^{-}$4/2008 (IN - SLTI 4/2008), que passou a vigorar em janeiro de 2009 . Ainda em 2008, destacam-se também os Acórdãos 1.603/2008 e 2.471/2008 do TCU, que tratam amplamente de recomendações acerca de como devem ser gerenciados e formulados os processos de aquisição de serviços de TI por parte dos órgãos da APF.

A IN - SLTI 4 é um importante normativo que, assim que foi publicado, causou grande impacto nos órgãos que compõem o Sistema de Administração dos Recursos de Tecnologia da Informação (SISP). Este, em resposta, propôs, em sua Estratégia Geral de Tecnologia da Informação (EGTI),

"um conjunto de objetivos e ações voltadas a adequar o arcabouço institucional e gerencial, de modo que se viabilizasse a transição entre a situação existente anteriormente à edição da IN - SLTI 4/2008 e o pleno cumprimento das novas normas relativas à contratação dos serviços de TI" (Henkin; Selao, 2010, p.75).

Contudo, apesar do andamento das ações institucionais relacionadas a IN SLTI 4, como a publicação do guia prático para contratação de soluções de TI e treinamentos para servidores públicos, observase uma lacuna no que se refere ao acompanhamento e monitoramento da real adoção do processo proposto.

Alguns estudos que abordam as contratações de TI no setor público relatam problemas em decorrência da falta de formalização do processo de contratação, falta de conhecimento sobre ele e das deficiências na sua execução (GuARDA, 2011; Barbosa et al., 2006; CArdoso, 2006).

Um levantamento com abordagem direta, porém sem aprofundamento, sobre o processo de contratação de TI foi o autodiagnóstico aplicado aos diferentes órgãos da APF no ano de 2009 e 2010 pela SLTI, no qual foram realizadas apenas duas perguntas genéricas: "A área de TI possui um processo formal de aquisição de bens

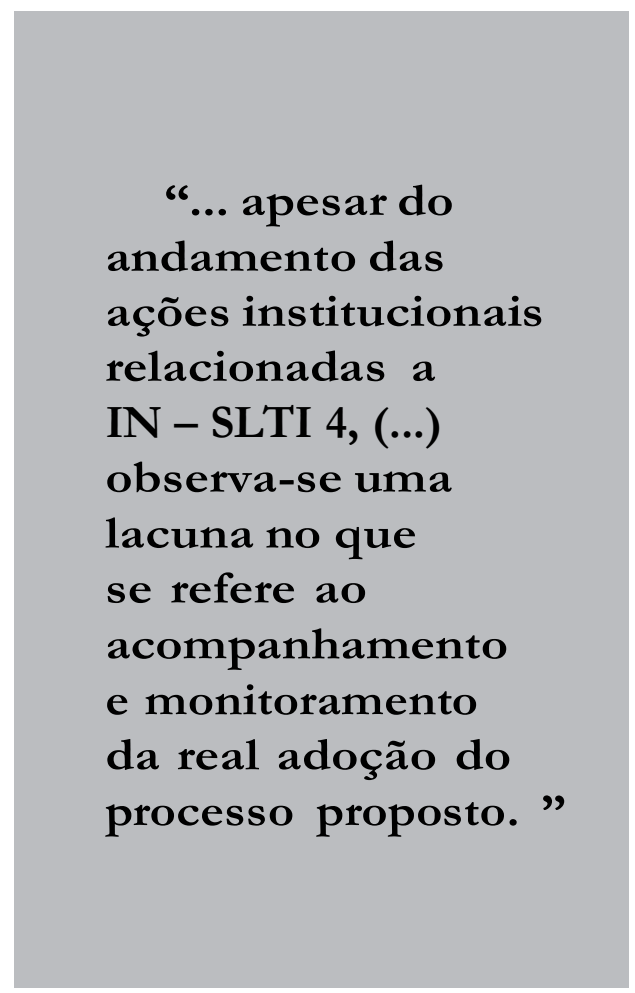

e serviços?" e "O processo está alinhado com a IN - SLTI 4/2008?”, tornando o instrumento insuficiente para uma análise mais detalhada do assunto.

Para este estudo foi elaborado um instrumento avaliativo que visa a identificar a conformidade do processo de contratação de soluções de TI em execução em uma entidade pública com o processo 
descrito no "Guia prático para contratação de soluções de Tecnologia da Informação versão 1.1" baseado na IN - SLTI 4/2010, considerando contratações a partir de 2011.

Além de explicitar quais atividades estão ou não conformes ao normativo, esse instr umento também propõe uma autoavaliação da maturidade para cada uma das três fases da IN - SLTI 4/2010: Planejamento da Contratação de Soluções de TI (PCTI), Seleção do Fornecedor de Soluções de TI (SFTI) e Gerenciamento do Contrato de Soluções de TI (GCTI).

Sendo assim, durante o desenvolvimento deste artigo é mostrado o panorama geral das legislações relacionadas às contratações no setor público, com ênfase na IN - SLTI 4 , sendo o referencial teórico completado com considerações acerca de modelos de avaliação de maturidade e de conformidade de processos. A seção seguinte traz a descrição dos procedimentos metodológicos utilizados na pesquisa, em que o Ministério Público Brasileiro (MPB) é também situado como universo da pesquisa, cujo processo de aquisições de TI está em elaboração e será baseado na IN - SLTI 4/2010. Após os ajustes decorrentes em um estudo-piloto aplicado em uma instituição pertencente ao $\mathrm{MPB}$, esse instrumento foi utilizado em um levantamento nacional com participação de 13 ministérios públicos, que representam cerca de $43 \%$ do total, obtendo-se o panorama atual desse segmento público com relação aos processos de compras de soluções de TI. Finalizando, realiza-se a análise dos dados obtidos e apresentam-se as conclusões.

Espera-se que este estudo possa contribuir com um mecanismo eficaz para medir e analisar a evolução e o grau de implementação, conformidade e maturidade dos processos de contratação propostos na IN - SLTI 4, como sugerido por Henkin e Selao (2010, p.94), permitindo uma aplicação regular para formação de uma base histórica de uso interno ou externo.

Este trabalho poderá auxiliar também no entendimento da aceitabilidade e aplicabilidade dos referidos processos na esfera da administração pública federal brasileira, em especial contribuindo para que o normativo no âmbito do MPB, ao ser elaborado e proposto, considere a real situação de suas instituições.

\section{Referencial teórico}

\section{Normativos aplicáveis às contra- tações no setor público}

A garantia de conformidade com os requisitos legais e regulatórios é considerada um dos pilares da g overnança corporativa de TI (ABNT, 2009) que está em consonância com a Constituição Federal brasileira, conforme o princípio da legalidade, pelo qual as ações do administrador público devem ser pautadas pela legislação e jurisprudência em vigor (BRASIL, 1988, art. 37, caput).

Os gestores públicos brasileiros enfrentam um grande desafio para atender a toda legislação e normativos aplicáveis ao setor público, mesmo quando se reduz o escopo para processos de contratação de soluções de TI. A criação e institucionalização desses processos envolvem frequentemente ações complexas, como:

"a identificação dos requisitos necessários, a garantia da qualidade dos resultados esperados, os critérios de aceitação, a gestão de mudanças, as transferências de conhecimentos, a legislação pertinente, entre outros. E envolvem também questões de relacionamento entre clientes e fornecedores, $\mathrm{o}$ 
que implica competências administrativas e jurídicas" (Cruz, 2011).

Segundo Cruz (2008), o normativo aplicável às contratações de serviços de TI é bastante extenso e o processo de sua catalogação não é simples. Devem-se considerar os aspectos constitucionais, de organização administrativa, orçamentários, de licitações e contratos, de direito autoral, de segurança da informação e crimes digitais, relativos a políticas governamentais e de requisitos das instâncias do controle, além de se considerar as normas e modelos de governança de TI: ISO/IEC 38500 e Cobit; normas e modelos de melhoria de processo de software: ISO/IEC 12207, ISO/IEC 15504, CMM, CMMI, MPS.BR; modelos de capacidade em contratações: e SCM-SP, e SCM-CL; modelos com foco em aquisição de software: IEEE STD 1062, SA-CMM, CMMI-ACQ, Guia de Aquisição-MPS.BR.

Diante desse cenário, Cruz (2008) criou o Quadro Referencial Normativo para contratações de serviços de TI no setor público (QRN), que foi reconhecido como referencial para orientação de gestores por meio do Acórdão 1.215/2009-TCU-Plenário (BRAsil, 2009) aplicável ao Executivo, Judiciário, Legislativo e Ministério Público.

"O QRN foi elaborado com base em um modelo genérico do processo de contratação de serviços no setor público (organizado em fases, atividades e etapas) compilado a partir de modelos de referência. Contém 289 entendimentos condensados (corolários) que sumarizam os requisitos legais extraídos de 153 fontes da legislação, jurisprudência e outras fontes auxiliares" (CRUZ, 2008).

Somando-se a esse conjunto de legislações, normas, modelos e jurisprudências para contratação, também é necessário considerar os regulamentos internos ao órgão, como a política de segurança da informação (PSI), além da legislação e da jurisprudência específicas sobre os processos de trabalho que a solução apoiará, como considerar a Lei $n^{\circ} 8.112 / 1990$ na aquisição de um sistema de gestão de recursos humanos (BrasiL, 2012, p. 42).

Em seu "Guia de Boas Práticas em Contratação de Soluções de Tecnologia da Informação: Riscos e Controles para o Planejamento da Contratação”, o TCU ressalta um dos aspectos mais importantes das contratações, que é a prática conhecida como "terceirização de serviços". Encontra-se no Decreto-Lei nº200/1967, art. 10, $\int 7^{\circ}$ a diretriz para que a APF se desobrigue da execução de tarefas operacionais, recorrendo, sempre que possível, à execução indireta, desde que a iniciativa privada esteja suficientemente desenvolvida na área, bem como não haja comprometimento da segurança nacional.

O Decreto $n^{\circ} 2.271 / 1997$ regulamentou, trinta anos depois, a diretriz de execução indireta contida no $\int 7^{\circ}$ do art. 10 do Decreto-Lei 200/1967 e incluiu as atividades de informática no rol de serviços que devem ser preferencialmente objeto de execução indireta (Decreto 2.271/1997, art. 1', $\left.\int 1^{\circ}\right)$. Posteriormente, a IN - SLTI 4/2008 regulamentou a execução indireta de serviços de TI, à luz da legislação corrente (Leis $8.666 / 1993$ e 10.520/2002) e da jurisprudência sobre o assunto, que, depois, foi atualizada pela IN - SLTI 4/2010. As normas citadas, bem como muitas outras, regulamentam o uso de montante considerável aplicado em TI pela APF.

Por fim, a fundamentação legal citada é, em grande parte, aplicável a toda a APF. Contudo, alguns normativos não são de observância obrigatória por alguns órgãos, 
a exemplo do Decreto $\mathrm{n}^{\circ} 2.271 / 1997$, que não se aplica a entidades como as estatais, e de instruções normativas da SLTI que não são de cumprimento obrigatório para órgãos não pertencentes ao SISP. Entretanto, são considerados boas práticas em contratação, sendo a adoção voluntária desses normativos recomendada pelo TCU (BrasiL, 2012, p.16).

\section{A Instrução Normativa $n^{\circ} 4 / 2010$ da SLTI}

No âmbito da APF, para os órgãos integrantes do SISP no Poder Executivo federal, o processo de contratação de soluções de TI passou a ser objeto de legislação específica a partir da edição da Instrução Normativa n ${ }^{\circ} 4 / 2008$, que foi publicada inicialmente em maio de 2008 e depois atualizada em novembro de 2010 e, novamente, em fevereiro de 2012 pela IN - SLTI 2/2012.

Cabe registrar que o fato de ter sido elaborada uma Instrução Normativa específica para serviços de TI

"implica a admissão de que a natureza e o processo da compra de serviços de Tecnologia da Informação possuem características que os distinguem da natureza e do processo de compra de outros serviços; caso contrário, seria suficiente a legislação então vigente sobre compras governamentais (leis e instruções normativas sobre licitações, pregões, entre outros aspectos das aquisições de bens e serviços pela administração pública federal)" (Henkin; Selao, 2010).

O conjunto de normas e regras que constituem a IN - SLTI 4/2008, 3/2009 e 4/2010 foram derivadas de recomendações dos Acórdãos 786/2006, 1.480/2007, $1.999 / 2007,2.471 / 2008$ e $1.915 / 2010$, todos do Plenário do TCU. Observa-se, no entanto, que a IN - SLTI 2/2012 não se encontra alinhada às recomendações daquele órgão, pois afirma, contrariamente às recomendações do TCU, a não aplicabilidade da IN - SLTI 4 para:

"I - as contratações em que a contratada for órgão ou entidade, nos termos do art. 24, inciso VIII da Lei $\mathrm{nt}^{\circ}$ 8.666, de 1993, ou empresa pública, nos termos do art. $2^{\circ}$ da Lei no 5.615 , de 13 de outubro de 1970, modificado pela Lei $\mathrm{n}^{\circ}$ 12.249, de 11 de junho de 2010; e

II - as contratações cuja estimativa de preços seja inferior ao disposto no art. 23, inciso II, alínea " $a$ " da Lei $\mathrm{n}^{\circ}$ 8.666, de 1993” (Brasil, 2012a).

A Figura 2 mostra a estrutura da norma que traz, no seu primeiro capítulo, dois importantes mecanismos de governança que apoiam a contratação de soluções em TI. O primeiro é a Estratégia Geral de Tecnologia da Informação (EGTI), elaborada pelo órgão central em conjunto com os órgãos setoriais e seccionais do SISP, que é revisada anualmente e contém orientações gerais para as áreas de TI dos órgãos e entidades da APF e entidades integrantes do SISP (art. 3\%).

Em seguida, a norma aborda a obrigatoriedade do "planejamento, elaborado em har monia com o Plano Diretor de Tecnologia da Infor mação (PDTI), alinhado ao planejamento estratégico do órgão ou entidade.” (art $\left.4^{\circ}\right)$. Fica, portanto, estabelecido que os órgãos e entidades da APF devem realizar seus processos de aquisição de serviços de TI de forma que estejam orientados e alinhados por instrumentos estratégicos, sejam institucionais ou específicos de TI de cada órgão. A ênfase no processo de planejamento se refere a mais 
de uma dimensão: o planejamento de cada contratação deve ser precedido pelo PDTI de cada órgão e estar alinhado com este, que, por sua vez, deve estar em consonância com as estratégias gerais do órgão ou entidade da APF à qual pertence, bem como com as diretrizes da EGTI do SISP.

No segundo capítulo, encontra-se o processo de contratação de serviços de TI, constituído das fases de planejamento da contratação, de seleção do fornecedor e de gerenciamento do contrato, que também é considerado um importante mecanismo de governança para contratação de soluções em TI (Cruz, 2011).

Na fase PCTI, observam-se os cuidados com a definição das responsabilidades dos envolvidos, justificativas e resultados esperados e fonte de recursos. Essa fase tem início com o recebimento do Documento de Oficialização da Demanda (DOD) pela Área de Tecnologia da Informação, oriundo da Área Requisitante da Solução. A Figura 3 elenca as etapas do Planejamento da Contratação com base no guia prático para contratação de soluções de Tecnologia da Informação versão 1.1 .

Conforme o art. 21 da IN - SLTI 4/ 2010, "a fase de Seleção do Fornecedor terá início com o encaminhamento do Termo de Referência ou Projeto Básico pela Área de Tecnologia da Informação à área de licitações", cabendo à última a responsabilidade pela fase. Além disso, caberá à área de TI:

- apoiar tecnicamente o pregoeiro ou a Comissão de Licitação nas respostas aos questionamentos ou às impugnações dos licitantes; e

- apoiar na análise e julgamento das propostas e dos recursos apresentados pelos licitantes.

Essa fase é encerrada com a assinatura do contrato e com a nomeação de pessoas para exercerem os papéis de: gestor do contrato; fiscal técnico do contrato; fiscal requisitante do contrato; e fiscal administrativo do contrato. A Figura 4 mostra o detalhamento dessa fase, com as principais etapas da SFTI.

Instrução

Normativa

SLTI 4/2010

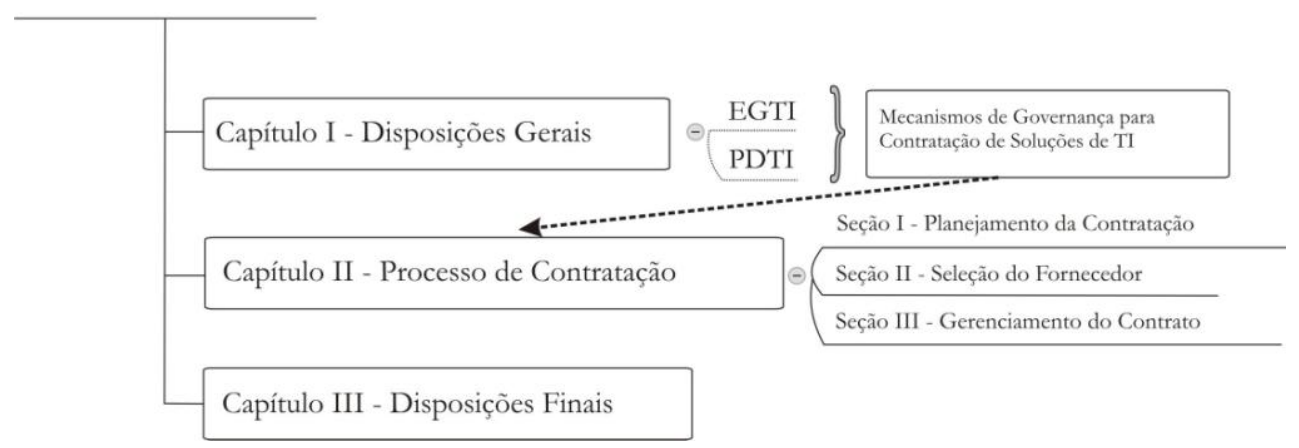

Fonte: Brasil, 2012a. Adaptado pelos autores.

Figura 2: Estrutura da IN - SLTI 4/2010 atualizada pela IN - SLTI 2/2012 


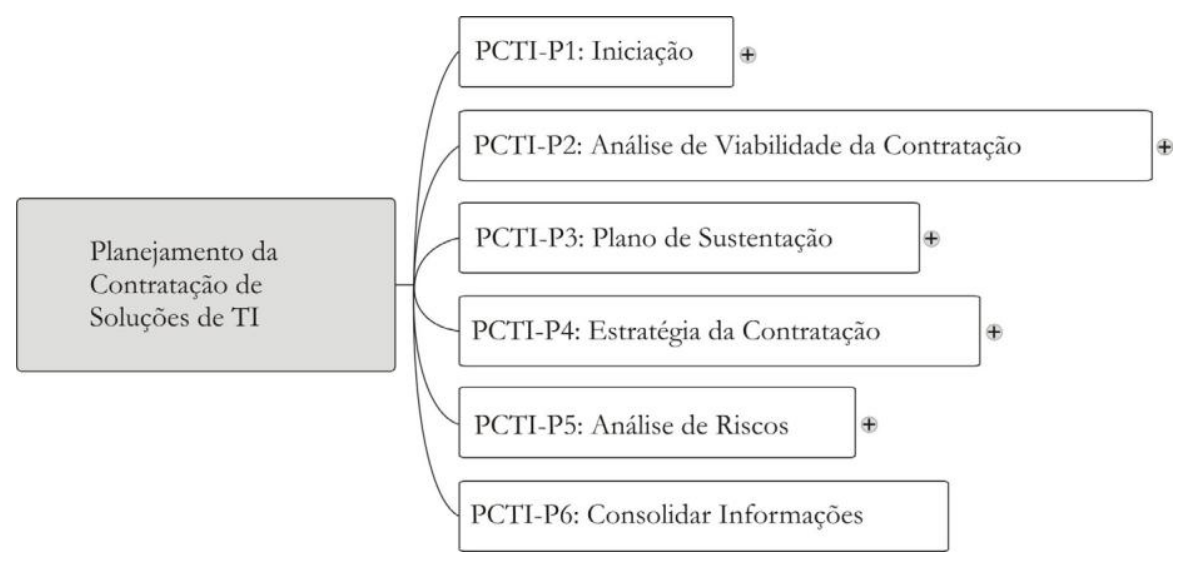

Fonte: Brasil, 2012a. Adaptado pelos autores.

Figura 3: Etapas do Planejamento da Contratação de Soluções de TI (PCTI)

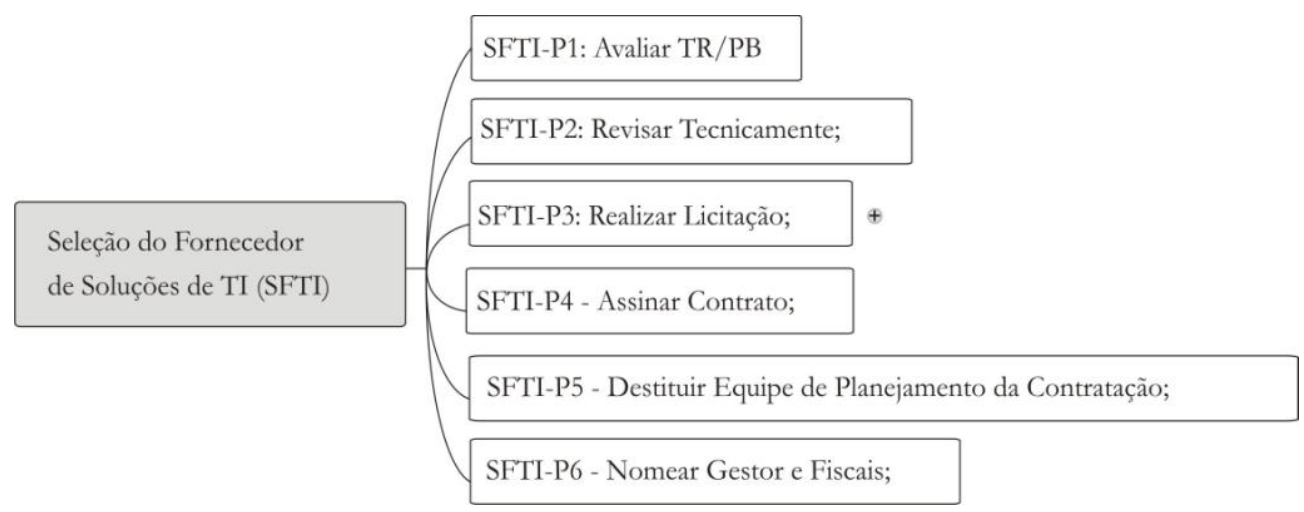

Fonte: Brasil, 2012a. Adaptado pelos autores.

Figura 4: Etapas da Seleção do Fornecedor de Soluções de TI (SFTI)

O GCTI, de acordo com o art. 25 da IN - SLTI 4/2010, "visa a acompanhar e garantir o fornecimento dos bens e a adequada prestação dos serviços que compõem a solução de tecnologia da informação durante todo o período de execução do contrato", e conta com as etapas descritas na Figura 5.

\author{
Avaliação da conformidade com a \\ IN - SLTI 4/2010 \\ Segundo definição da norma ABNT \\ NBR ISO/IEC 17000:2005, a avaliação da \\ conformidade é a "demonstração de que \\ os requisitos especificados relativos a um \\ produto, processo, sistema, pessoa ou \\ organismo são atendidos" (ABNT, 2005).
}




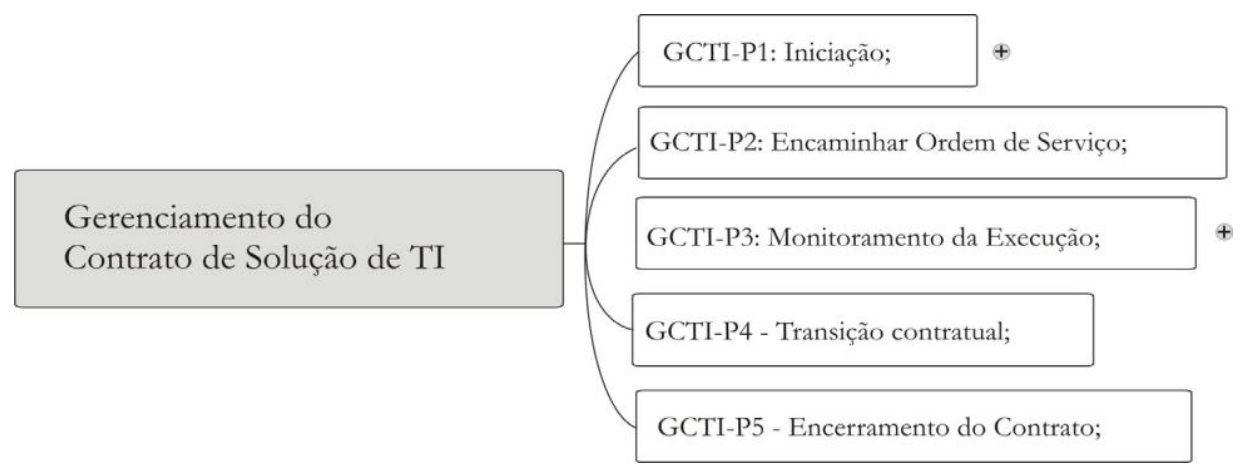

Fonte: Brasil, 2012a. Adaptado pelos autores.

Figura 5: Etapas do Gerenciamento do Contrato de Soluções de TI (GCTI)

Apesar de o processo de contratação de soluções de TI estar definido e detalhado no Modelo de Contratação de Soluções de Tecnologia da Informação (MCTI), proposto no "Guia prático para contratação de soluções de Tecnologia da Informação versão 1.1", e que se baseia nas fases e processos descritos na IN 4/2010, esse modelo não oferece uma proposta para avaliação de conformidade (BRASIL, 2011).

Portanto, para se executar esse tipo de aferição, é necessário considerar o que seriam os requisitos do referido processo e os critérios para atendimento dos mesmos. O MCTI é composto por fases que contêm fluxos ou processos, atividades, artefatos e atores, conforme a Tabela 1.

Poder-se-ia considerar, por exemplo, que os requisitos especificados para o
MCTI se traduzem na forma dos artefatos gerados para cada uma de suas fases, concluindo-se que, se os artefatos existem, a fase está em conformidade. Essa abordagem, no entanto, tem alguns pontos de falha: um artefato pode ter sido gerado sem a execução de alguma atividade como prevê o modelo, ou mesmo posteriormente, quebrando o fluxo de um processo. Há também a questão do vocabulário adotado na denominação dos artefatos, pois, apesar de apresentarem uma descrição, não existe uma taxonomia ou uma ontologia que certifique que o entendimento é padronizado e comum nas diferentes instituições que devem seguir o normativo.

Com essas observações e considerando a definição de requisito como uma característica ou condição indispensável para a

Tabela 1: Distribuição dos Processos, Atividades, Artefatos e Atores do MCTI

\begin{tabular}{lcccc}
\hline Fases & Processos & Atividades & Artefatos & Atores \\
\hline PCTI & 5 & 41 & 8 & 7 \\
\hline SFTI & 3 & 7 & 1 & 4 \\
\hline GCTI & 5 & 19 & 4 & 5 \\
\hline
\end{tabular}

Fonte: Brasil, 2011. 
existência ou execução do processo, o item "Atividades" apresenta-se como o melhor candidato para aferição da conformidade. Afinal, para as atividades serem executadas, é necessária a participação dos atores e o seu resultado final é a criação, atualização ou eliminação de algum artefato. Além disso, essas atividades ocorrem segundo um fluxo mapeado, agregando, em consequência, todos os componentes das fases do MCTI. Em resumo, ao se avaliar a execução ou não de cada uma das atividades, deve ser possível demonstrar que os requisitos relativos ao processo são atendidos, evidenciando que há conformidade ou não com a norma.

Dada a natureza dinâmica dos processos, é possível existirem instâncias diferentes de um mesmo processo acontecendo simultaneamente, onde as atividades que o compõem podem ocorrer em uma instância, mas terem sido negligenciadas em outra. Logo, a utilização de checklists com opções binárias só funcionaria para avaliar a conformidade de cada instância do processo, o que poderia tornar a avaliação demorada, prejudicando sua eficiência quanto ao provimento de informações gerenciais em tempo hábil.

Por isso, é conveniente considerar o uso de uma escala Likert, que permite aos avaliados se posicionarem em diversos níveis, e analisarem, para um conjunto de contratações de TI, se uma atividade é realizada sempre, nunca ou às vezes (conforme a granularidade escolhida para a escala), em vez de analisarem individualmente cada contratação.

O critério para medir a conformidade pode ser, portanto, a execução ou não das atividades de cada fase, considerando um período e um conjunto de contratações. Por exemplo, se no ano de 2011 ocorreram cinco contratações de TI e somente em três delas $(60 \%)$ a atividade $\mathrm{A}$ foi executada e a atividade $\mathrm{B}$ ocorreu em todas as cinco instâncias do processo (100\%), a fase composta pelas atividades A e B não pode ser considerada $100 \%$ conforme, pois apenas $50 \%$ da fase (atividade B) é sempre executada. Logo, seria considerado 50\% de conformidade para esse exemplo.

Cabe ressaltar que o uso da escala Likert também proporciona uma oportunidade para análise mais detalhada, pois, no exemplo acima, apesar de haver um nível de conformidade de apenas 50\%, é possível observar que o esforço para se alcançar um índice de 100\% consiste em aumentar o índice de execução da atividade A de $60 \%$ para $100 \%$.

\section{Avaliação da maturidade de processos}

A IN - SLTI 4/2010 se destaca entre os diversos modelos ou processos com foco em aquisição de software, como o Guia de Aquisição-MPS.BR, o CMMI for Acquisition (CMMI-ACQ) e o COBIT, por ser aplicada à realidade da gestão pública brasileira e alinhada à nossa legislação. Porém, o MCTI não provê uma ferramenta, modelo ou orientações para a medição da maturidade do processo.

A Melhoria do Processo de Software Brasileiro (MPS.BR) é um programa coordenado pela Associação para Promoção da Excelência do Software Brasileiro (SOFTEX), composto por diversos documentos. O Guia Geral 2009 descreve a estrutura do modelo e dos níveis de maturidade, processos e capacidade, resultados esperados e oferece uma visão geral dos guias de implementação dos níveis, do processo de avaliação e do guia de aquisição (SOFTEX, 2009).

Nesse modelo, cada nível de maturidade representa uma combinação entre processos 
e suas capacidades, com uma evolução caracterizada por sete estágios de melhoria (de A a G), possibilitando prever o desempenho da organização a partir da implementação de um ou mais processos. Observa-se que o Processo Aquisição AQU encontra-se no Nível F - Gerenciado, o que significa, nesse modelo, que é acrescido pelos processos do nível de maturidade anterior e dos demais processos do nível F: Garantia da Qualidade; Gerência de Configuração; Gerência de Portfólio de Projetos; e Medição (SOFTEX, 2009). É, portanto, um modelo de maturidade bem específico e aplicável somente no contexto proposto no MPS.BR.

Já o CMMI-ACQ versão 1.3 provê orientação para a aplicação das melhores práticas CMMI pelo contratante, que são focadas em atividades para iniciar e gerir a aquisição de produtos e serviços que atendam às necessidades do cliente (SEI, 2010). Quanto à avaliação, o documento se refere ao Appraisal Requirements for CMMI (ARC), que descreve os requisitos para se criar modelos para diferentes tipos de avaliações, variando a formalidade em três classes, em que a classe A é definida como um método formal para um benchmarking completo. Conforme a finalidade da avaliação e natureza das circunstâncias, pode-se elaborar uma autoavaliação, uma breve avaliação inicial ou uma avaliação externa (SEI, 2010). De qualquer forma, o CMMI-ACQ não detalha uma avaliação de maturidade específica para os processos de aquisições de TI, mas se apoia no ARC, que é considerado uma referência para se entender ou propor modelos de avaliação.

O COBIT 4.1 é um framework para gerenciar e controlar as atividades de TI, com uma compilação de boas práticas divididas em quatro domínios, num total de 34 processos (ITGI, 2007). Entre esses, o domínio de Aquisição e Implementação é o que está mais relacionado à contratação de serviços de TI, embora processos de outros domínios também sejam referenciados.

Para o ITGI (2007), o propósito do modelo de maturidade é identificar onde os problemas estão e como estabelecer prioridades para melhorias, e não simplesmente avaliar o nível de aderência aos objetivos de controle. Analisar a maturidade de um processo COBIT deve permitir à organização identificar o estágio atual da

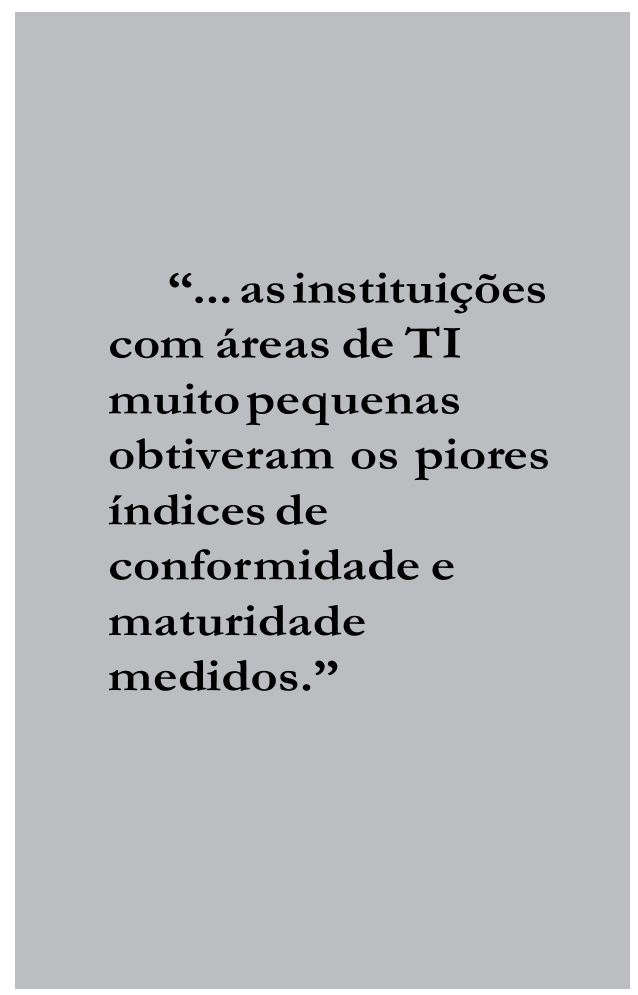

empresa, o estágio atual do mercado (benchmarking), a maturidade pretendida e o caminho a ser percorrido para sair da situação atual para a situação futura. Cada processo do COBIT é avaliado segundo uma escala genérica, complexa, e que exige uma visão completa e sistêmica da organização, que é apresentada no Quadro 1 (Xavier, 2010). 


\section{Quadro 1: Maturidade do COBIT 4.1}

\begin{tabular}{|l|l|}
\hline 0 - Inexistente & $\begin{array}{l}\text { Completa falta de um processo reconhecido. A orga- } \\
\text { nização nem mesmo reconheceu que existe uma } \\
\text { questão a ser trabalhada. }\end{array}$ \\
\hline 1 - Inicial / Ad hoc & $\begin{array}{l}\text { Existem evidências de que a organização reconhe- } \\
\text { ceu a existência de questões que precisam ser traba- } \\
\text { lhadas. No entanto, não existe processo padroniza- } \\
\text { do; ao contrário, existem enfoques ad hoc que tendem } \\
\text { a ser aplicados individualmente ou caso a caso. O } \\
\text { enfoque geral de gerenciamento é desorganizado. }\end{array}$ \\
\hline 2 - Repetível, & $\begin{array}{l}\text { Os processos evoluíram para um estágio em que pro- } \\
\text { cedimentos similares são seguidos por diferentes pes- } \\
\text { porém, fazendo a mesma tarefa. Não existe um treina- } \\
\text { mento for mal ou uma comunicação dos } \\
\text { procedimentos padronizados e a responsabilidade é } \\
\text { deixada com o indivíduo. Há um alto grau de confi- } \\
\text { ança no conhecimento dos indivíduos e, } \\
\text { consequentemente, erros podem ocorrer. }\end{array}$ \\
\hline 3 - Definido & $\begin{array}{l}\text { Procedimentos foram padronizados, documentados } \\
\text { e comunicados por meio de treinamento. É requeri- } \\
\text { do que esses processos sejam seguidos; no entanto, } \\
\text { possivelmente, desvios não serão detectados. Os pro- } \\
\text { cedimentos não são sofisticados, mas existe a } \\
\text { formalização das práticas existentes. }\end{array}$ \\
\hline Mensurável & $\begin{array}{l}\text { A gerência monitora e mede a aderência aos proce- } \\
\text { dimentos e adota ações quando os processos não } \\
\text { estão funcionando bem. Os processos são constan- } \\
\text { temente aprimorados e fornecem boas práticas. } \\
\text { Automação e ferramentas são utilizadas de uma ma- } \\
\text { neira limitada ou fragmentada. }\end{array}$ \\
\hline $\begin{array}{l}\text { Os processos foram refinados em um nível de boas } \\
\text { práticas e são continuamente aprimorados. A TI é } \\
\text { utilizada como uma opção para automatizar o fluxo } \\
\text { de trabalho, provendo ferramentas para aprimorar a } \\
\text { qualidade e efetividade, tornando a organização rá- } \\
\text { pida em adaptar-se. }\end{array}$ \\
\hline \multirow{2}{*}{ - Otimizado }
\end{tabular}

Fonte: ITGI, 2007, p.21. Adaptado pelos autores. 
O COBIT 4.1 oferece uma abordagem para avaliação da maturidade em que cada processo apresenta um modelo de maturidade próprio, tornando este um modelo muito específico para avaliação da maturidade e único para cada um dos 34 processos. Porém, esse framework, após um estudo intitulado IT Governance and Process Maturity (ITGI, 2008), passou a apresentar também uma proposta com operacionalização simplificada e genérica por meio do uso de atributos.

Esse modelo genérico prevê a identificação de seis atributos referenciais (Sensibilização e Comunicação; Políticas, Planos e Procedimentos; Ferramentas e Automação; Habilidades e Conhecimento; Responsabilidade e Responsabilização; e Metas e Mensuração). Tais atributos são organizados em uma escala de 0 a 5 $(0=$ não existente, $1=$ inicial ou ad hoc, $2=$ repetível, mas intuitivo, $3=$ definido, 4 = gerenciado e mensurável, e $5=$ otimizado) que permite a sua aplicação para qualquer processo, eliminando a necessidade de utilizar o modelo de maturidade específico de cada processo, bastando utilizar a Tabela de Maturidade de Atributos parcialmente mostrada no Quadro 2 (Xavier, 2010).

\section{Procedimentos metodológicos}

Ao explicitar quais atividades estão ou não em conformidade com o normativo, os conhecimentos sobre o processo e as deficiências na sua execução podem ser aplicados de forma imediata e eficaz nas instituições envolvidas, evidenciando os problemas vivenciados nessas organizações quanto à execução do processo conforme prediz a norma.

A avaliação da percepção da maturidade das fases do processo por parte dos gestores de TI também proporciona um conjunto de informações que podem ser utilizadas pelos gestores envolvidos em seus planejamentos futuros, seja na implementação de ações corretivas ou controles ou, até mesmo, na manutenção de determinado nível de maturidade alcançado.

Este estudo pode, então, ser caracterizado, quanto à sua natureza, como uma pesquisa aplicada, pois "visa a fornecer subsídios para a resolução de problemas práticos" (Gondim e Lima, 2006).

\section{Quadro 2: Trecho da Tabela de Maturidade de Atributos (nível de maturidade 1)}

\begin{tabular}{|c|c|c|c|c|c|}
\hline $\begin{array}{l}\text { Sensibilização e } \\
\text { Comunicação }\end{array}$ & $\begin{array}{l}\text { Políticas, } \\
\text { Padrões e } \\
\text { Procedimentos }\end{array}$ & $\begin{array}{l}\text { Ferramentas e } \\
\text { Automatização }\end{array}$ & $\begin{array}{l}\text { Habilidades e } \\
\text { Conhecimento }\end{array}$ & $\begin{array}{l}\text { Responsabilidades } \\
\text { e Prestação de } \\
\text { Contas }\end{array}$ & $\begin{array}{l}\text { Estabelecimento } \\
\text { de Metas e } \\
\text { Avaliação }\end{array}$ \\
\hline \multicolumn{6}{|c|}{ Nivel 1} \\
\hline $\begin{array}{l}\text { Um } \\
\text { reconhecimento } \\
\text { emergente para } \\
\text { a necessidade do } \\
\text { processo. Há } \\
\text { comunicação } \\
\text { esporádica das } \\
\text { questões. }\end{array}$ & $\begin{array}{l}\text { Existem } \\
\text { abordagens ad } \\
\text { boc para os } \\
\text { processos e } \\
\text { práticas. O } \\
\text { processo e as } \\
\text { políticas são } \\
\text { indefinidos. }\end{array}$ & $\begin{array}{l}\text { Algumas } \\
\text { ferramentas } \\
\text { podem existir, } \\
\text { mas seu uso é } \\
\text { baseado em } \\
\text { ferramentas } \\
\text { padrão de } \\
\text { desktop. Não há } \\
\text { uma abordagem } \\
\text { planejada para o } \\
\text { uso das } \\
\text { ferramentas. }\end{array}$ & $\begin{array}{l}\text { As habilidades } \\
\text { necessárias para } \\
\text { o processo não } \\
\text { são identificadas. } \\
\text { Não existe um } \\
\text { plano de } \\
\text { formação e } \\
\text { nenhum } \\
\text { treinamento } \\
\text { formal ocorre. }\end{array}$ & $\begin{array}{l}\text { Não há definição } \\
\text { de } \\
\text { responsabilidades } \\
\text { e prestação de } \\
\text { contas. As } \\
\text { pessoas se } \\
\text { apropriam das } \\
\text { questões com } \\
\text { base em sua } \\
\text { própria iniciativa, } \\
\text { de forma reativa. }\end{array}$ & $\begin{array}{l}\text { Objetivos não } \\
\text { são claros e } \\
\text { nenhuma } \\
\text { medição ocorre. }\end{array}$ \\
\hline
\end{tabular}

Fonte: Xavier, 2010. 
Neste estudo, os dados coletados expressam a percepção dos respondentes, indicando uma interpretação do fenômeno e configurando uma característica qualitativa. Por outro lado, essas opiniões puderam ser traduzidas em números com o objetivo de análise apoiada em recursos e técnicas estatísticas como a média, percentagem e mediana, indicando uma característica quantitativa.

Quanto aos fins, o aspecto descritivo desta pesquisa fica claro pois "expõe as características de determinada população ou de determinado fenômeno" (VERGARA, 1998, p. 45) ao investigar o universo do Ministério Público Brasileiro. Ela também pode ser considerada exploratória, já que envolveu levantamento bibliográfico e entrevistas com os gestores responsáveis pelos processos de governança de TI e contratações de soluções de TI em suas organizações, e pesquisa documental, em especial a procura e seleção de normativos como os Acórdãos do TCU relacionados a contratações de TI. Como meio de investigação (ou procedimento técnico), foi utilizado o levantamento que, "mediante a utilização de questionários e entrevistas estruturadas, possibilita o conhecimento direto da realidade e a quantificação dos fenômenos, além de permitir a obtenção de resultados com relativa rapidez e economia" (GIL, 2009, p. 9).

O protocolo de trabalho incluiu as atividades prévias, como a escolha do MPB como universo para pesquisa, a elaboração de questionário e identificação dos responsáveis em cada instituição e uma apresentação presencial dos objetivos e procedimentos da pesquisa, estabelecendo o período para respostas, por ocasião de encontro realizado com a alta direção das áreas de Tecnologia da Informação dos MP brasileiros em outubro de 2012. As atividades posteriores ao levantamento de dados foram o envio de relatório consolidado com uma análise dos dados e o agradecimento aos respondentes.

Uma análise documental também foi realizada, em que se procurou identificar, no piloto e nas demais instituições, a existência de algum normativo, mapeamento de processo, mecanismo de controle ou documento formal que tratasse especificamente do tema das contratações de TI. Além de ter sido realizado um estudo aprofundado da IN - SLTI 4/2010 e do seu guia prático para contratação de soluções de tecnologia da informação versão 1.1 .

Nas instituições participantes, a única documentação encontrada foi uma portaria regulamentadora do processo de contratações de TI na organização piloto. Ela foi analisada com especial atenção na identificação das atividades das fases da IN - SLTI 4/2010, por meio de um mapeamento entre os artigos da IN - SLTI 4/2010 e os artigos dispostos na portaria regulamentadora do órgão. Foi identificado que todos os artigos que descrevem atividades do processo são idênticos nos dois documentos. As diferenças encontradas foram nos artigos sobre planejamento prévio (PDTI e EGTI), e vedações e disposições finais, como o Art.32 da IN SLTI 4/2010 que trata da revogação da IN - SLTI 4/2008.

$\mathrm{O}$ instrumento proposto para medir a conformidade das contratações de soluções de TI com a IN - SLTI 4/2010 consistiu em um questionário com uso de escala Likert de 5 pontos, variando de " 0 - Nunca é realizada a 4 -É realizada para todas as demandas", composto pelas atividades das fases, como pode ser observado na Figura 6. Essa escala é amplamente utilizada e força os entrevistados a indicar o grau de concordância ou discordância das variáveis apresentadas (MALHOTRA, 2001). 


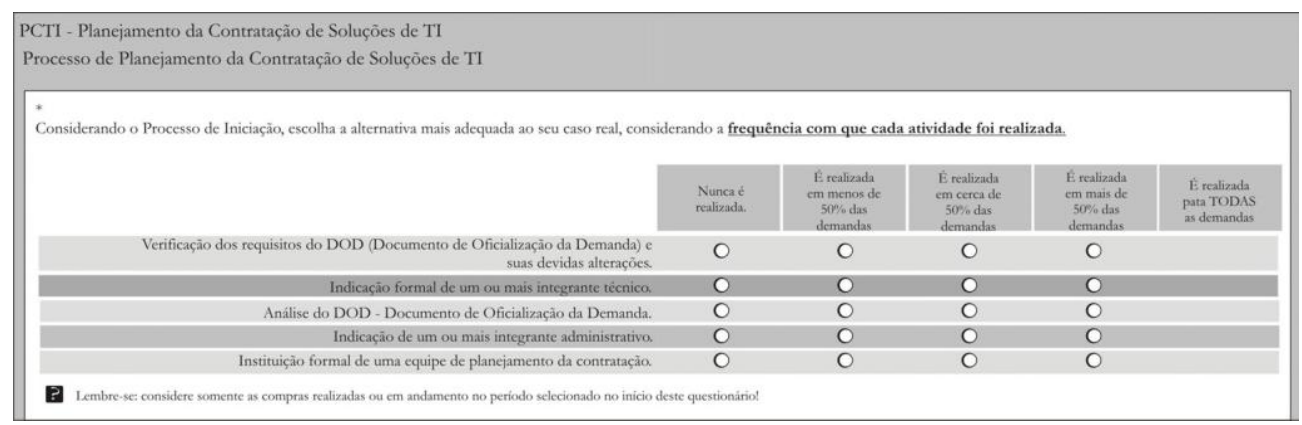

Fonte: Elaboração própria.

\section{Figura 6: Exemplo de pergunta do questionário}

O critério para determinar a conformidade dos processos de contratação com a IN - SLTI 4/2010 foi a verificação de quantas atividades de cada fase foram realizadas para todas as demandas. $\mathrm{Ou}$ seja, em um primeiro momento, se a atividade foi realizada em mais de $50 \%$ das demandas, ela não está em conformidade com a norma, pois se espera que seja sempre executada, e não apenas executada na maioria das vezes. Contudo, essa informação é considerada na análise dos dados, para se identificar quais atividades ou fases estão mais próximas de serem consideradas em conformidade e quais estão em pior situação. Sendo assim, uma fase com sete atividades, em que cinco foram informadas como "realizada para TODAS as demandas", tem uma conformidade de aproximadamente $71 \%$ com a IN - SLTI 4/2010, para uma instituição em particular.

Ao se considerar o conjunto de instituições que participaram da pesquisa, objetivando gerar um panorama geral da conformidade, os dados obtidos foram classificados por meio do percentual de instituições que responderam "realizada para TODAS as demandas" para cada atividade. A partir daí, utilizou-se a média desses percentuais encontrados nas atividades para se obter a conformidade da etapa ou processo.

A Tabela 2 apresenta o resumo desses percentuais, mostrando um detalhamento para o PCTI e outro para o Plano de Sustentação, que é parte do PCTI. Ou seja, considerando o Plano de Sustentação, 15\% das instituições respondentes indicaram que a atividade (a definição dos recursos materiais) é "realizada para TODAS as demandas". A média de 13\% para o Plano de Sustentação é resultado dos valores informados para as atividades dessa etapa, que aparecem na parte inferior da tabela. Por sua vez, a média encontrada para o Plano de Sustentação é considerada no cálculo da média de 31\% do Planejamento de Contratações de TI e esta, junto com os valores obtidos similarmente para a Seleção de Fornecedores de TI (69\%) e Gerenciamento do Contrato da Solução de TI (46\%), geram o valor médio de 48\% de conformidade dos Processos de Contratação dos MP brasileiros com a IN04.

$\mathrm{Na}$ seção "Avaliação da conformidade com a IN-SLTI 4/2010” deste artigo foi apresentado o modelo de maturidade por atributos do COBIT 4.1, que é genérico o suficiente para permitir a sua aplicação a qualquer processo, bastando utilizar a Tabela de Maturidade de Atributos. Com 
Tabela 2: Cálculo da conformidade dos processos com a IN - SLTI 4/2010

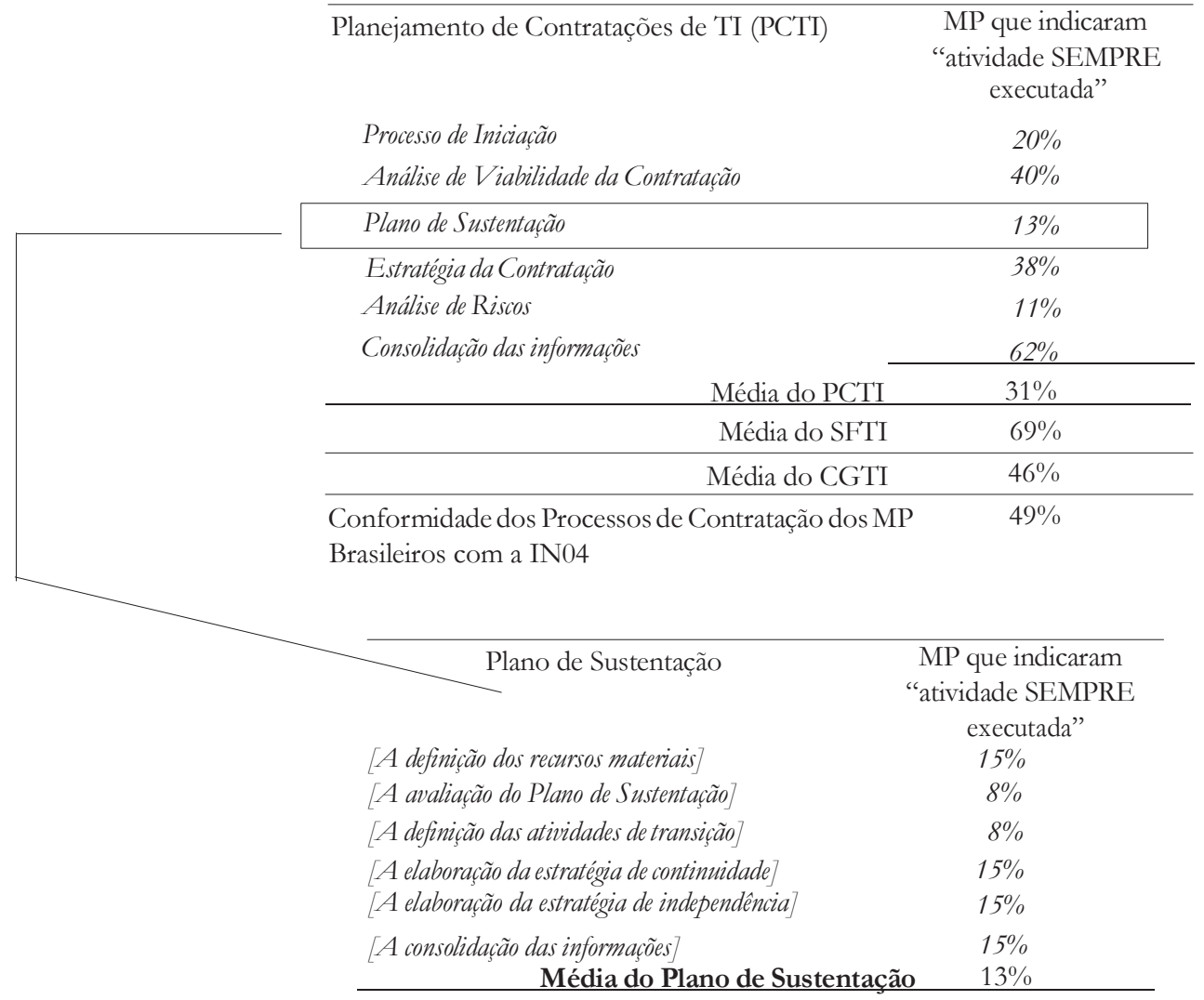

Fonte: Elaboração própria.

isso, o questionário foi elaborado para medir também a maturidade de cada fase do processo, PCTI, SFTI e GCTI. A Figura 7 traz um exemplo para o atributo Consciência e Comunicação com a escala para autoavaliação por meio da escolha do nível mais adequado à organização. Como a escala não oferece valores intermediários, os respondentes foram orientados a se posicionarem no nível em que todas as características fossem atendidas, ou seja, o nível de menor maturidade no caso de dúvida entre dois níveis.

A Tabela 3 mostra o detalhamento da medição e cálculo da maturidade da fase
PCTI para uma instituição participante, em que os resultados obtidos para cada um dos seis atributos são utilizados para o cálculo da média que identifica o nível de maturidade para aquela fase. Para consolidação e visão geral do segmento MPB, a média foi novamente utilizada após o cálculo individual de cada instituição participante.

A aplicação do questionário no piloto foi realizada com três participantes de diferentes cargos na hierarquia da instituição, sendo todos conhecedores do processo de aquisições de TI em vigor, e teve por objetivo possibilitar um melhor 


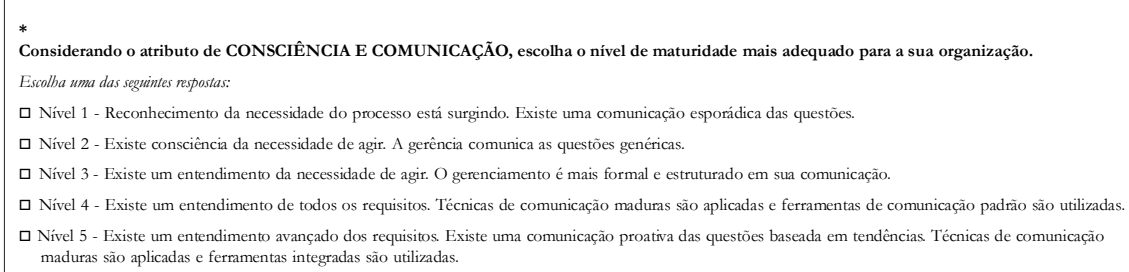

Fonte: Elaboração própria.

Figura 7: Exemplo de pergunta sobre maturidade do PCTI no questionário

Tabela 3: Maturidade do PCTI de uma instituição

\begin{tabular}{|c|c|c|c|c|c|c|}
\hline \multicolumn{7}{|c|}{ MP3 } \\
\hline 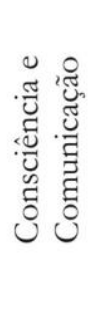 & 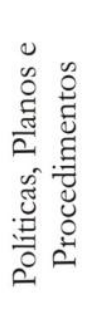 & 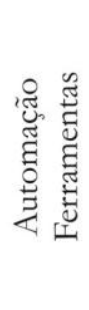 & 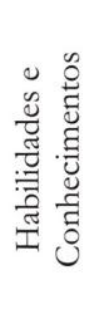 & 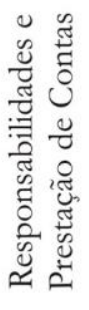 & 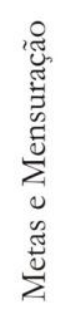 & $\frac{\pi}{\frac{\pi}{2}}$ \\
\hline 2,00 & 3,00 & 1,00 & 2,00 & 3,00 & 3,00 & 2,33 \\
\hline
\end{tabular}

Fonte: Elaboração própria.

ajuste no instrumento de pesquisa, obtendo-se diferentes visões e críticas. Para as demais instituições participantes, o questionário foi aplicado somente com um participante.

A coleta de dados do piloto foi referente a aquisições realizadas pelo órgão no período de janeiro de 2011 a setembro de 2012. Cada respondente não tomou conhecimento das respostas dos demais e despendeu aproximadamente uma hora para responder a todo o questionário, em dias distintos.

Alguns dos ajustes necessários foram: o acréscimo de um breve resumo sobre o escopo da IN - SLTI 4, esclarecendo que o questionário deveria ser respondido baseado nas compras reais - que ocorreram no período indicado pelo respondente - que fossem acima de $\mathrm{R} \$ 80.000,00$, que é o limite estabelecido pelo normativo; e a explicitação de qual processo estava sendo avaliado na maturidade em cada um dos atributos, para não confundir com o processo completo da IN - SLTI 4.

Também foram coletadas características acerca do tamanho da área de TI de cada instituição, com participação de 13 ministérios públicos que representam cerca de $43 \%$ do total, assim como informações acerca das estruturas e mecanismos de gover nança de TI, com a finalidade de apoiar o processo de inferência dos resultados. 


\section{Universo da pesquisa: o Minis- tério Público Brasileiro}

Em 1988, a Constituição Federal fez referência expressa ao Ministério Público no capítulo "Das funções essenciais à Justiça", definindo as funções institucionais, as garantias e as vedações de seus membros. A partir de então, na área cível, o Ministério Público adquiriu novas funções, destacando a sua atuação na tutela dos interesses difusos e coletivos, como meio ambiente; consumidor; patrimônio histórico, turístico e paisagístico; pessoa portadora de deficiência; criança e adolescente; comunidades indígenas e minorias ético-sociais.

O Ministério Público Brasileiro pode ser entendido como a composição das instituições: Ministério Público da União (MPU), que engloba o Ministério Público Federal, o Ministério Público do Trabalho, o Ministério Público Militar e o Ministério Público do Distrito Federal e Territórios; e o Ministério Público do Estado (MPE), presente em cada um dos 26 estados brasileiros. Essas instituições têm assegurada sua autonomia funcional, administrativa e financeira, sendo similar à estrutura do Judiciário, sem, no entanto, fazer parte do mesmo.

Todas essas instituições respondem a um único órgão de controle externo e de fiscalização do exercício administrativo e financeiro: o Conselho Nacional do Ministério Público (CNMP). Desde sua criação, em 2004, pela Emenda Constitucional $\mathrm{n}^{\circ} 45$, o CNMP tem mostrado preocupação com o planejamento estratégico e a atuação das áreas de Tecnologia da Informação, por meio de resoluções e recomendações. Para melhor se estruturar, no intuito de compartilhar experiências, promover estudos, coordenar atividades e fixar políticas e padrões em TI, foi criado o Comitê de Políticas de Tecnologia da Informação do Ministério Público, o CPTI-MP, exclusivo para as áreas de Tecnologia da Informação dos Ministérios Públicos (MP), com a participação da alta direção.

Apesar de não fazer parte do Sistema de Administração dos Recursos de Tecnologia da Informação e, portanto, não estar diretamente obrigado a seguir a IN - SLTI 4/2010, o CNMP recebeu recomendações do TCU por meio do Acórdão nº 1.603/2008 no item 9.1.6, do Acórdão no 1.233/2012 no item 9.16 e do Acórdão $\mathrm{n}^{\mathrm{a}} 54 / 2012$ no item 9.4, para que:

"9.4.1. oriente os órgãos e as entidades do Ministério Público da União a executar as seguintes ações nas contratações de serviços de TI:

9.4.1.1. elaborar estudos técnicos preliminares, à semelhança do disposto no art. 10 da IN SLTI/MPOG 4/ 2008, previamente à elaboração dos termos de referência e projetos básicos, inclusive nos casos de dispensa e inexigibilidade de licitação, em atenção ao art. 6, inciso IX, alínea "e", da Lei 8.666/1993;

9.4.1.2. elaborar plano de trabalho, inclusive nos casos de dispensa e inexigibilidade de licitação, em atenção ao disposto no art. $2^{\circ}$ do Decreto 2.271/1997;

9.4.1.3. instruir cada processo de contratação com termo de referência ou projeto básico à luz do item 9.1 do Acórdão nº 2.471/2008 - Plenário, inclusive nos casos de dispensa e inexigibilidade de licitação, em atenção ao disposto no inciso II do art. 21 do Decreto $\mathrm{n}^{\circ} 3.555 / 2000$, no inciso IX do art. $6^{\circ}$ da Lei $n^{\circ} 8.666 / 1993$, e no art. 17 da IN SLTI/MPOG 4/2008; 


\section{$[\ldots]$}

9.4.1.6. observar o disposto na IN SLTI/MPOG 4/2008, com relação à gestão contratual, em especial o art. 14, incisos II e III, e o art. 20, inclusive nos casos de dispensa ou inexigibilidade de licitação, em atenção ao art. $6^{\circ}$, inciso IX, alínea " $\mathrm{e}$ ", da Lei $\mathrm{n}^{\circ}$ 8.666/1993;

9.4.1.7. designar formalmente o preposto da contratada, inclusive nos casos de dispensa ou inexigibilidade de licitação, em atenção ao art. 68 da Lei no 8.666/1993" (BRASIL, 2012b).

Com base nessas recomendações, em reunião do CPTI ocorrida em outubro de 2012, foi instituído um grupo de trabalho para elaborar a minuta da resolução sobre contratações de TI baseada na IN - SLTI 4/2010, válida para o MPB. Esse trabalho foi apoiado com a aplicação do questionário discutido neste estudo.

\section{Resultados obtidos}

Os resultados obtidos para o grau de maturidade de cada processo foram consolidados utilizando-se a média, como pode ser observado na Figura 8.

A conformidade dos processos com a IN - SLTI 4/2010, por sua vez, está resumida na Tabela 4.

Por fim, foram criadas duas tabelas agrupando as atividades com os maiores índices de não execução e os maiores índices de execução, em cada uma das três fases: PCTI, SFTI e GCTI. As Tabelas 5 e 6 mostram uma parte dos resultados encontrados para o PCTI com essa abordagem.

\section{Análise dos resultados}

Como pode ser observado na Figura 9, as áreas de TI muito pequenas (de $1 \mathrm{a}$ 15 pessoas) representam apenas $15 \%$ da amostra. É esperado que essa quantidade

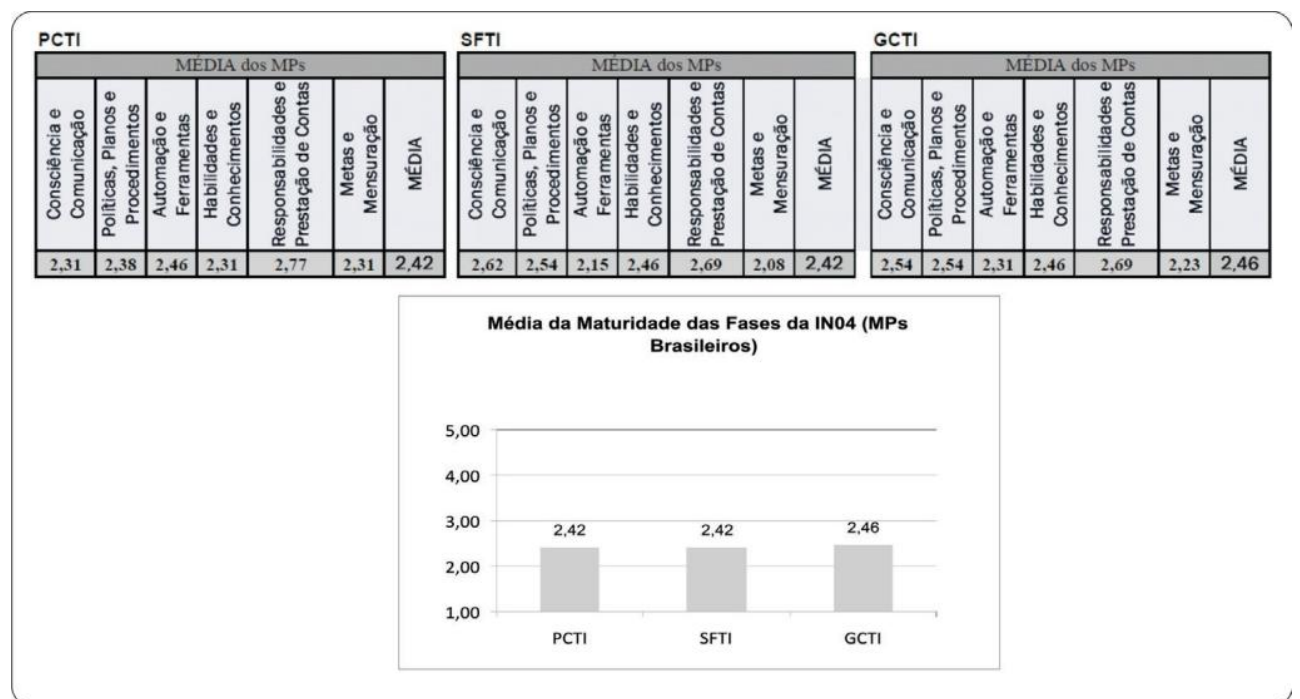

Fonte: Elaboração própria.

Figura 8: Média da maturidade dos processos da IN - SLTI 4/2010 
Tabela 4: Resumo dos índices de conformidade

\begin{tabular}{cc}
\hline Fase da IN - SLTI 4/2010 & $\begin{array}{c}\text { Respondentes que indicaram } \\
\text { "atividade SEMPRE executada" }\end{array}$ \\
\hline Média do PCTI & $31 \%$ \\
\hline Média do SFTI & $69 \%$ \\
\hline Média do GCTI & $46 \%$ \\
\hline $\begin{array}{c}\text { Conformidade dos processos de } \\
\text { contratação dos respondentes } \\
\text { com a IN04 }\end{array}$ & $49 \%$ \\
\hline
\end{tabular}

Fonte: Elaboração própria.

Tabela 5: "Não execução" das atividades no PCTI

\begin{tabular}{|c|c|c|}
\hline \multicolumn{3}{|c|}{ PCTI - Atividades que "NUNCA SÃO REALIZADAS" } \\
\hline Iniciação & $\begin{array}{l}\text { [Instituição formal de uma equipe de planejamento da } \\
\text { contratação] }\end{array}$ & $69 \%$ \\
\hline \multicolumn{3}{|c|}{ PCTI- Atividades realizadas "MENOS QUE 50\%" (inclui: nunca e < 50\%) } \\
\hline Plano de Sustentação & [Avaliação do plano de sustentação] & $92 \%$ \\
\hline Iniciação & $\begin{array}{l}\text { [Instituição formal de uma equipe de planejamento da } \\
\text { contratação] }\end{array}$ & $85 \%$ \\
\hline Plano de Sustentação & [Elaboração da estratégia de independência] & $77 \%$ \\
\hline Plano de Sustentação & [Elaboração da estratégia de continuidade] & $69 \%$ \\
\hline Plano de Sustentação & [Consolidação das informações] & $69 \%$ \\
\hline Análise de riscos & [Identificação de danos potenciais] & $62 \%$ \\
\hline Análise de riscos & $\begin{array}{l}\text { [Identificação de riscos de não atendimento das } \\
\text { necessidades] }\end{array}$ & $62 \%$ \\
\hline Análise de riscos & [Consolidação das informações e a avaliação da análise de risco] & $62 \%$ \\
\hline
\end{tabular}

Fonte: Elaboração própria. 
Tabela 6: "Execução" das atividades no PCTI

\begin{tabular}{|c|c|c|}
\hline \multicolumn{3}{|c|}{ PCTI - Atividades que "SEMPRE SÃO REALIZADAS” } \\
\hline $\begin{array}{c}\text { Análise de } \\
\text { Viabilidade }\end{array}$ & hição de requisitos] & $54 \%$ \\
\hline \multicolumn{3}{|c|}{ PCTI - Atividades realizadas "MAIS QUE 50\%" (inclui: sempre e > $50 \%$ ) } \\
\hline Estratégia Contratação & [Indicação da solução de TT] & $85 \%$ \\
\hline Estratégia Contratação & [Indicação dos termos contratuais] & $77 \%$ \\
\hline Estratégia Contratação & [Definição das responsabilidades da contratada] & $77 \%$ \\
\hline Análise de Viabilidade & [Definição de requisitos] & $62 \%$ \\
\hline
\end{tabular}

Fonte: Elaboração própria.

de recursos humanos se traduza em deficiências na execução de um processo complexo como o de aquisições de TI, o que foi verificado, pois as instituições com áreas de TI muito pequenas obtiveram os piores índices de conformidade e maturidade medidos.

Nota-se, também, que 54\% das instituições possuem um Comitê Estratégico de TI (CETI), mas apenas $8 \%$ possuem um Plano Estratégico de TI (PETI). Como abordado na introdução deste artigo, a governança de TI tem uma ligação direta com aquisições e investimentos, e a existência de um CETI favorece o controle e acompanhamento das compras de TI. Já a falta de um PETI e um índice modesto de instituições com PDTI podem ter

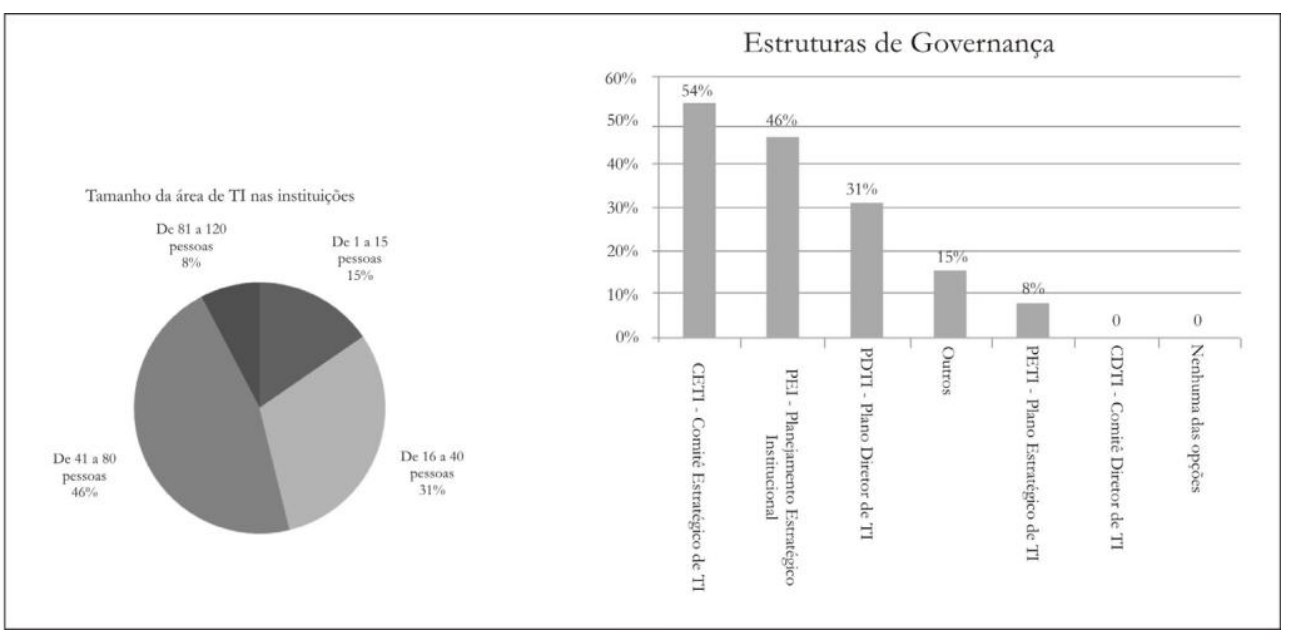

Fonte: Elaboração própria.

Figura 9: Características da amostra 
contribuído para que a fase com maior foco em planejamento, a PCTI, tenha sido a fase com o menor índice de conformidade.

Observando-se as fases da IN - SLTI 4/2010 para a organização piloto, verificouse, conforme a Figura 10, que a SFTI tem o melhor índice de conformidade, pouco acima da média nacional medida para esse segmento público. O GCTI obteve índices medianos, mas também acima da média nacional, e o PCTI foi a fase com o menor índice de conformidade, o que seguiu a tendência encontrada nos outros órgãos.

O PCTI é a fase com maior quantidade de artefatos, atividades e atores, o que a torna mais complexa. Entretanto, vale ressaltar que o planejamento adequado das contratações cria condições para que os órgãos executem a seleção de fornecedor e gestão contratual com maior probabilidade de êxito e de forma mais segura (BRASIL, 2012).
Ainda segundo o TCU (2012), o planejamento da contratação é fundamental para que:

1) a contratação agregue valor ao órgão;

2) os riscos envolvidos sejam gerenciados;

3) a contratação esteja alinhada com o planejamento do órgão e de sua TI, bem como com o planejamento do órgão governante superior ao qual esteja vinculado; e

4) os recursos envolvidos sejam bem utilizados, não só os recursos financeiros, mas também os recursos humanos.

Salienta-se que planejamento é um princípio fundamental que deve permear toda a atuação da APF, como consta no Decreto-Lei $\mathrm{n}^{\circ}$ 200/1967, art. 6o, inciso I e art. 10, J 7․ Adicionalmente, na IN SLTI 4/2010, art. 4ํㅜ consta que as contratações de TI deverão ser precedidas

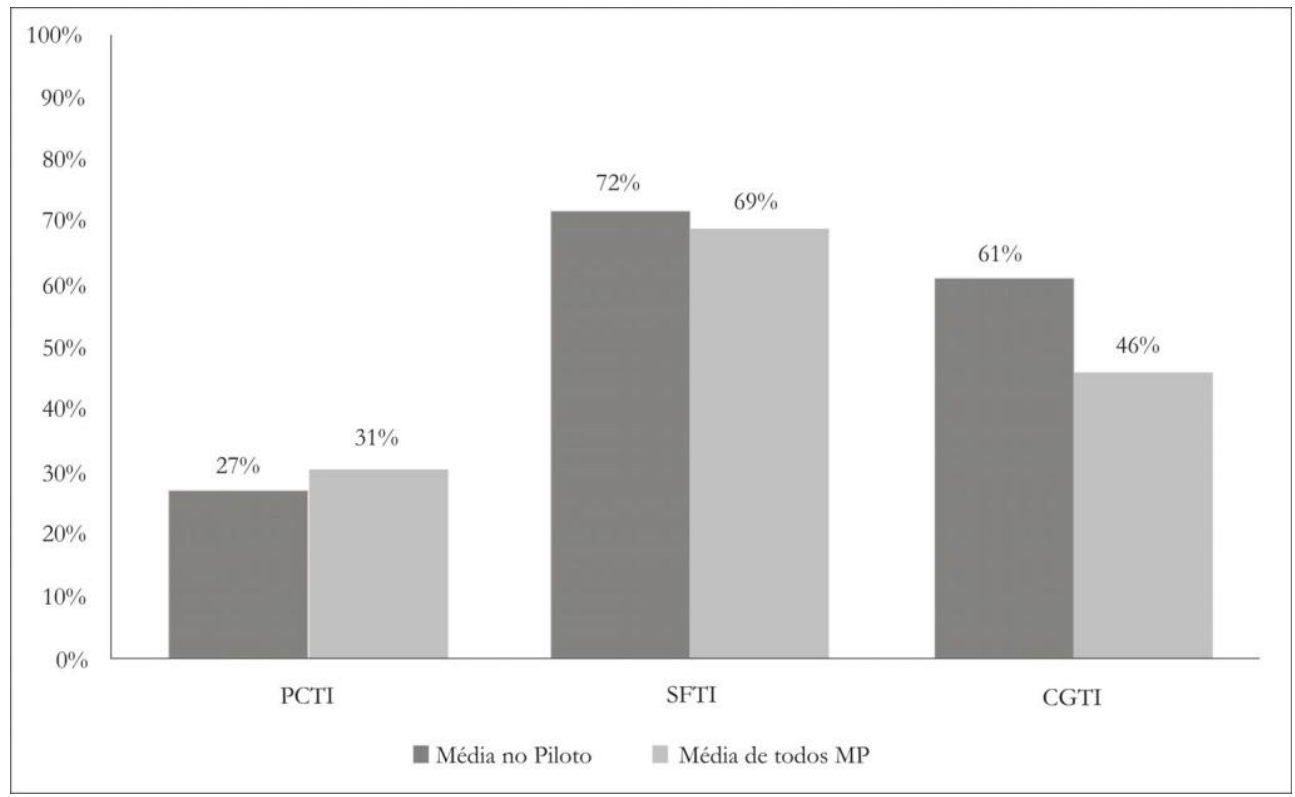

Fonte: Elaboração própria.

Figura 10: Média da conformidade para o PCTI, SFTI e GCTI (Piloto) 
de planejamento, elaborado em harmonia com o Plano Diretor de Tecnologia da Informação (PDTI), que, por sua vez, deverá estar alinhado com o planejamento estratégico do órgão (BRAsil, 2012, p. 21).

Além da complexidade, a percepção de maturidade mais baixa no PCTI pode ter sido influenciada pela falta dos planos PETI e PDTI, como comentado anteriormente, e também pela falta de entendimento de cada atividade pelos participantes, tendo em vista a introdução de um vocabulário novo, logo no primeiro artigo da norma, a falta de mapeamento do processo e a não existência de modelos dos artefatos citados, como o DOD, que foi verificado no piloto e pode se repetir nas outras instituições. Outro fator que pode ter contribuído para esse resultado está relacionado à forma de implantação do normativo na instituição-piloto, que, apesar de complexo, entrou em vigor na data de sua publicação, sem prever uma transição ou iniciativas de sensibilização e capacitação.

Observando-se que a escala de maturidade não oferece níveis intermediários e que o questionário continha uma instrução para que se considerasse o nível mais baixo, no caso de não atendimento de todas as características descritas no nível em análise, a maturidade medida enquadra-se no nível 2, já que a média encontrada foi de 2,42 para os processos PCTI e SFTI, e de 2,46 para o GCTI. Segundo o modelo adotado, baseado no COBIT 4.1, nesse nível de maturidade:

"os processos evoluíram para um estágio em que procedimentos similares são seguidos por diferentes pessoas, fazendo a mesma tarefa. Não existe um treinamento formal ou uma comunicação dos procedimentos padronizados e a responsabilidade é deixada com o indivíduo. Há um alto grau de confiança no conhecimento dos indivíduos e, consequentemente, erros podem ocorrer" (ITGI, 2007, p.21).

A Figura 11 apresenta os resultados da avaliação de maturidade com o uso de diagramas de caixa, também conhecidos como Boxplot, cuja tendência central dos dados é feita utilizando a mediana, que não é afetada por modificações de valores abaixo ou acima dela, permitindo uma análise sem a interferência de valores discrepantes. A elaboração é feita a partir da determinação dos valores máximo e mínimo para a variável observada, além da mediana e do $1^{\circ}$ e $3^{\circ}$ quartis (HAIR et al, 2005 apud Xavier, 2012, p. 63).

O Boxplot ilustra a distribuição dos dados. O tamanho de cada quadrado branco indica que a amostra está pouco dispersa e que os valores são atípicos, indicados pelos asteriscos (respostas fora dos padrões observados para a maioria dos MP). Para o PCTI, duas instituições se posicionaram com uma percepção de alta maturidade, alcançando os níveis 4 - Gerenciado e Mensurável e 5 - Otimizado, e para o GCTI duas instituições se posicionaram no nível 4 - Gerenciado e Mensurável. Esses níveis de maturidade denotam um alto grau de aprimoramento e uso de boas práticas, incluindo ferramentas e automação, e se poderia esperar que processos tão maduros resultassem em um alto índice de conformidade. Isso foi observado, pois essas instituições obtiveram os maiores índices de conformidade também.

Além disso, a área representada pelos retângulos no PCTI e GCTI ilustra como a amostra encontra-se com valores muito próximos uns dos outros, sendo possível afirmar que a média de 2,42 realmente representa um valor válido para a maioria 


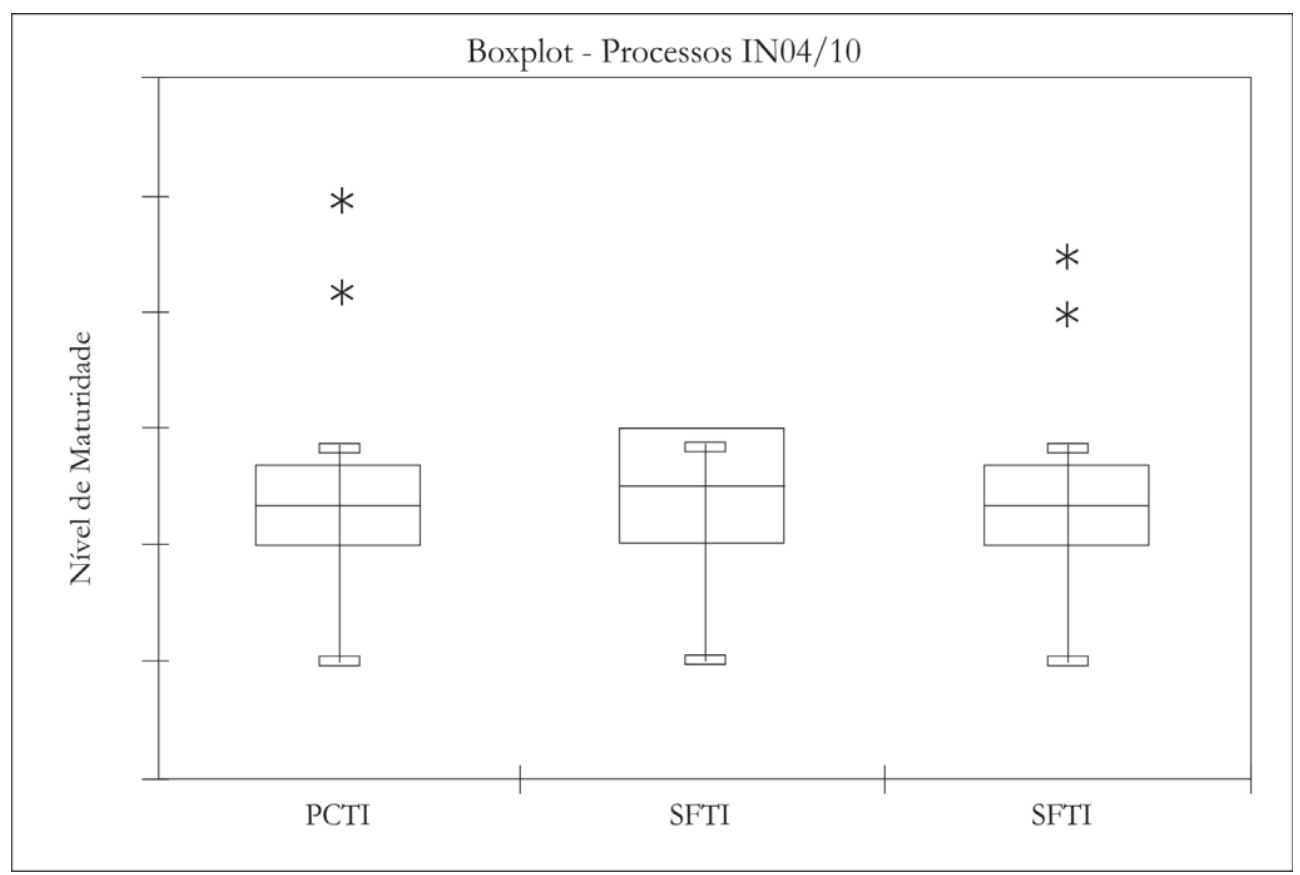

Fonte: Elaboração própria.

\section{Figura 11: Bloxplot dos Processos da IN - SLTI 4/2010 para o MPB}

dos casos, já que $75 \%$ da amostra (terceiro quartil) encontra-se abaixo de 2,7. Essa figura indica que ações para essas fases poderiam ser realizadas de maneira uniforme, pois atenderão à maioria dos casos que são relativamente similares uns aos outros. Para se estabelecer um conjunto de ações a serem tomadas sobre as fases, é necessário um detalhamento das metas de maturidade que se deseja alcançar; porém, essa avaliação não fez parte do escopo deste estudo, sendo uma oportunidade para trabalhos futuros.

Para a fase SFTI, a Figura 11 mostra um maior distanciamento dos valores ilustrado pelo retângulo ligeiramente maior que os do PCTI e GCTI. Sendo assim, apesar da média ter sido igual à da fase PCTI, é recomendável que ações de melhorias para o grupo de órgãos com maturidade mais próxima do nível 1 e 2 sejam diferentes das ações que atenderão às necessidades do grupo de instituições com maturidade mais próxima do nível 3 e 4 . Pelo fato de o grupo encontrar-se mais disperso, sugerese procurar soluções diferenciadas para os mesmos, caso se proponha um aumento na maturidade dessa fase do processo.

É importante ressaltar que a maturidade das fases diz respeito ao reconhecimento do processo pela organização, com padronização, documentação, monitoramento e controle, utilização de ferramentas automatizadas, utilização de boas práticas e preocupação com qualidade e efetividade dos processos, enquanto a conformidade se preocupa em verificar se os processos estão sendo executados como está descrito.

Sendo assim, um baixo nível de maturidade e um alto índice de conformidade para o SFTI podem indicar que, apesar de estarem sendo executadas, as atividades não 
são automatizadas, não há monitoramento e controle, ou mesmo padronização e documentação. Uma atividade como "Nomeação do gestor e fiscais do contrato", que é realizada em mais de $50 \%$ das demandas por $77 \%$ da amostra, ou seja, um bom índice de conformidade, em um ambiente de baixa maturidade, pode ocorrer em momentos diferentes do processo, ora junto com a assinatura do contrato, ora após o início da execução dos serviços, mas sempre acontece. Com um índice de maturidade elevado, seria possível afirmar que ela sempre ocorre em um momento específico do processo e que pode ser medida, por exemplo, pela quantidade de portarias com nomeações no período avaliado.

Para uma análise mais completa, é necessário responder à pergunta "Qual o nível de maturidade desejado para cada processo?". Essa meta pode ser estabelecida no plano de ação do CNMP para a transição e implantação do processo de contratações de soluções de TI a ser estabelecido por meio de uma resolução em nível nacional. Outra pergunta que pode subsidiar este trabalho seria: "É possível estabelecer o nível de maturidade por atributo para cada processo?".

Somente a análise da percepção da maturidade das fases não é suficiente para uma conclusão sobre a conformidade com a IN - SLTI 4/2010. Para isso, é necessário avaliar a execução das atividades de cada fase. Foram consideradas "conformes" aquelas atividades que foram executadas sempre, ou seja, para todas as contratações do período avaliado pelo gestor.

Para fins deste estudo, também foram destacadas as atividades que são menos executadas, ou seja, atividades que foram executadas em até "cerca de 50\% das demandas". Esselevantamento pode indicar os principais pontos de melhoria e necessidade de suporte para os MP no Brasil.

Observou-se que algumas atividades como "PCTI [Instituição Formal de uma Equipe de Planejamento da Contratação] e SFTI [Destituição da Equipe de Planejamento da Contratação]" tiveram um alto índice de não realização. Cerca de 69\% dos respondentes nunca realizaram essas atividades, chegando a $84 \%$ e $77 \%$ respectivamente, se considerarmos aqueles que executaram menos de $50 \%$ das demandas. Nota-se, nesse caso, que são atividades de responsabilidade da autoridade competente da área administrativa, o que pode indicar a falta de conhecimento do processo por parte da área administrativa e, consequentemente, a falha em assumir essa responsabilidade. A realização de um estudo mais detalhado sobre os motivos da não execução dessas atividades pode indicar fatores de sucesso ou barreiras na implantação da IN - SLTI 4/2010.

Sobre o PCTI, foi possível verificar que as atividades relacionadas ao Plano de Sustentação e Análise de Riscos são as menos executadas; logo, deve-se avaliar detalhadamente a viabilidade de implantação dessas atividades, procurando-se estabelecer qual o suporte necessário em termos de pessoal, treinamento, consultoria, modelos, entre outras atividades e mecanismos disponíveis. Esse é também o processo com mais atividades e que percentualmente apresentou mais deficiências. De um total de 32 atividades, somente 13 são realizadas em mais de $50 \%$ das demandas.

Apesar das fases PCTI, SFTI e GCTI terem alcançado o mesmo nível de maturidade pela autoavaliação dos gestores, a frequência com que as atividades são realizadas no SFTI é consideravelmente maior que nas outras fases, com índices de 77\% 
a $92 \%$ de realização para todas as atividades, exceto "Destituição da Equipe de Planejamento da Contratação", ou seja, próximo de se alcançar a conformidade completa com a IN - SLTI 4/2010 para a maior parte da amostra. Logo, as ações necessárias são no sentido de se melhorar a maturidade dos órgãos provendo ferramentas automatizadas, modelos e consultoria, se assim for necessário.

Para o GCTI, apenas três atividades chamam a atenção, a Atividade de Encerramento do Contrato, Elaboração do Plano de Inserção pelo Gestor do Contrato e Transição Contratual, por apresentarem os piores índices de execução para esse processo. Contudo, ao analisar a outra ponta da escala, ou seja, execução acima de $50 \%$, apenas quatro atividades (de um total de 12) se enquadram nessa categoria. Dessa forma, observa-se a existência de uma maior distribuição, com parte das atividades apresentando péssima execução, uma parte na média e outra parte próxima do ideal, não sendo possível, portanto, afirmar que o GCTI está mais próximo de estar conforme do que não conforme.

\section{Conclusões}

O mecanismo proposto pode se tornar um eficaz instrumento para a governança de TI de uma instituição, ao medir a percepção da conformidade com um normativo de alta relevância. Ele pode, também, trazer à luz pontos de melhoria na comunicação e propostas de controles inter nos que fortaleçam a gestão e governança de TI.

Os resultados obtidos mostraram que, para o Ministério Público Brasileiro, a conformidade com o normativo IN - SLTI 4/2010 é baixa, alcançando uma média de 48\%. Considerando a relevância do tema, tanto em termos financeiros quanto para a g overnança de TI, esse é um nível preocupante de aderência ao normativo. Apesar de recente, a IN - SLTI 4/2010 não altera leis ou regulamentos sobre licitações, mas as complementa e fornece uma estrutura de processo, conceitos e artefatos que orientam as compras de soluções de TI, com bastante ênfase no planejamento. Logo, a falta de conformidade com a mesma poderia indicar uma falha grave no cumprimento de leis, assim como deficiências na governança e planejamento de TI. Ao se observar com detalhe quais atividades são mais prejudicadas, é possível inferir que, para o Ministério Público Brasileiro, a baixa conformidade está relacionada à segunda hipótese: falhas na governança e planejamento de TI.

Por outro lado, vale ressaltar que a IN - SLTI 4/2010 não se aplica diretamente a esse segmento governamental, e que esse resultado poderá ser utilizado na criação e implantação do seu próprio normativo, considerando, por exemplo, um período de transição para que realmente seja possível a adequação do pessoal e das rotinas das instituições impactadas.

A etapa de Seleção do Fornecedor da Solução de TI é a que se encontra mais próxima da conformidade total com a INSLTI 4/2010. O Planejamento da Contratação de Soluções de TI, por sua vez, é o que apresenta os piores índices.

Uma limitação do mecanismo proposto é a não exigência da formalização do processo executado nas instituições para compará-lo à IN - SLTI 4/2010. Segundo o TCU:

"um processo de trabalho somente se torna formal quando está documentado e publicado pelo ator competente (e.g. dirigente máximo do órgão), que 
se compromete com a adoção efetiva do processo ao formalizá-lo. Além disso, somente pode ser considerado como implantado quando é feita a divulgação do processo junto aos executores e demais interessados e, se necessário, é realizado o treinamento dessas pessoas. Por fim, um processo somente é considerado como utilizado quando há evidências da sua adoção pelos executores.” (BRAsIL, 2012, p. 16).

Essa falta de formalização aumenta o grau de incerteza e poderia ter impactos na qualidade dos dados obtidos. Segundo Gil, "é comum entre os leitores de estudos de caso serem feitas indagações acerca de sua validade. $\mathrm{Ou}$, em outras palavras: os leitores querem saber se os resultados obtidos referem-se de fato à realidade estudada ou à interpretação do pesquisador" (GIL, 2009, p. 111). Por outro lado, foram tomados cuidados em relação à representatividade dos participantes e à participação do pesquisador, no sentido de que sua presença não fosse reconhecida como uma ameaça ou que os dados fossem obtidos de maneira invasiva. Por exemplo, foi colocado claramente que o estudo não constituía uma auditoria e que as entidades seriam preservadas em sua identidade individual.

A avaliação da percepção da maturidade para cada fase do processo mostrou que os gestores classificam esses processos no nível 2, segundo o ITGI (2007): "Repetível, porém intuitivo. Os processos são estruturados e procedimentos similares são seguidos por diferentes indivíduos para a mesma tarefa. Há forte dependência do conhecimento individual e existe alguma documentação". Outra limitação neste estudo foi a de não ter medido o grau de maturidade desejado para esses processos. Com isso, seria possível estudar e propor ações que assegurassem o aumento da maturidade em conjunto com o aumento da conformidade, segundo as expectativas de cada instituição.

No entanto, as medições da conformidade e da maturidade do processo de aquisições de TI de forma isolada não trazem informações suficientes para se diagnosticar causas de falhas no mesmo. É necessário tecer considerações acerca dos recursos humanos necessários para uma execução em conformidade com IN - SLTI 4/2010. Além disso, o processo de planejamento de contratação de soluções de TI não ocorre isoladamente em uma instituição. Ele está inserido em um "contexto de diversos processos de trabalho [...], que influenciam não só a capacidade de produção de resultados das contratações de soluções de TI, como a própria viabilidade dessas contratações" (BRAsiL, 2012, p. 24).

Propõe-se, como estudos futuros, a investigação das barreiras e facilitadores na implantação da IN - SLTI 4/2010, e a aplicação do mecanismo proposto neste estudo para a avaliação da conformidade nas instituições do Executivo que têm por obrigação seguir a IN - SLTI 4/2010.

Concluindo, para garantir uma maior aderência ao processo é importante estabelecer controles formais e frequentes, além de ações que garantam publicidade, transparência e transferência de conhecimento em relação às boas práticas descritas no normativo, entendendo que os objetivos podem variar entre alcançar a conformidade e/ou alcançar um determinado nível de maturidade.

(Artigo recebido em fevereiro de 2013. Versão final em abril de 2013). 


\section{Referências bibliográficas}

AssociaÇÃo Brasileira de Normas Técnicas - ABNT. NBR ISO/IEC 38500:2009 — Governança corporativa de tecnologia da informação. Rio de Janeiro, 2009. 15 p.

NBR ISO/IEC 17000:2005. Avaliação de conformidade - Vocabulário e princípios gerais. Rio de Janeiro, 2005.

Associação para Promoção da Excelência do Software Brasileiro - SOFTEX. MPS.BR - Melhoria de Processo do Software Brasileiro - Guia geral. Campinas: SOFTEX, 2009. Barbosa, A. F.; Junqueira, A.R. B.; De Laia, M. M.; De Faria, F. I.. Governança de TIC e contratos no setor público. In: CATI - Congresso Anual de Tecnologia da InforMAÇão, 2006, São Paulo. Escola de Administração de Empresas de São Paulo da Fundação Getulio Vargas (FGV-EAESP), São Paulo, 2006.

Brasil. Decreto-Lei 200/1967. Diário Oficial da União. Seção 1, Brasilia, DF: Senado Federal, 1967.

. Constituição (1988). Constituição da República Federativa do Brasil. Brasilia, DF: Senado Federal, 1990. 210 p.

. Decreto 2.271/1997. Diário Oficial da União. Brasília, DF: Senado Federal, 1997.

. Acórdão no-1.603/2008 - Plenário. Brasília: Tribunal de Contas da União,

2008.

Acórdão no 1.215/2009 - Plenário. Brasília: Tribunal de Contas da União, 2009. Disponível em: http://www.lexml.gov.br/urn/urn:lex:br:tribunal.contas. uniao;plenario:acordao:2009-06-03;1215. Acesso em: 10/01/2013.

Tribunal de Contas da União. Acórdão 2.308/2010-TCU-Plenário. Relatório de levantamento. Avaliação da governança de tecnologia da informação na administração pública federal. 2010. Disponível em: http://www.lexml.gov.br/urn/urn:lex: br:tribunal.contas.uniao;plenario:acordao:2010-09-08;2308. Acesso em: 04/01/2013.

. Guia prático para contratação de soluções de tecnologia da informação versão 1.1. Brasília: SLTI/MPOG, 2011. Disponível em: http://www.governoeletronico.gov.br/ biblioteca/arquivos/guia-pratico-para-contratacao-de-solucoes-de-ti-mcti. Acesso em: 10/08/2012.

- Tribunal de Contas da União. Guia de boas práticas em contratação de soluções de tecnologia da informação: riscos e controles para o planejamento da contratação/Tribunal de Contas da União. Versão 1.0. Brasília: TCU, 2012. 527 p.

MPOG, 2010.

Instrução Normativa $n^{\circ}-4$, de 12 de novembro de 2010. Brasília: SLTI/ Instrução Normativa $n^{\circ}$ 2, de 14 de fevereiro de 2012. Brasília: SLTI/MPOG, $2012 \mathrm{a}$.

- Acórdão no-54/2012 - Plenário. Brasília: Tribunal de Contas da União,

2012b.

Cardoso, Gisele Silva. Processo de aquisição de produtos e serviços de software para administração pública do Estado de Minas Gerais. 2006. 166f. Dissertação (Mestrado em Ciência da Computação). Belo Horizonte, Universidade Federal de Minas Gerais, 26 de junho de 2006. 
Cruz, Cláudio Silva da. Governança de TI e conformidade legal no setor público: um quadro referencial normativo para a contratação de serviços de TI. 2008. 252f. Dissertação (Mestrado em Gestão do Conhecimento e da Tecnologia da Informação). Universidade Católica de Brasília, Brasília, 2008.

Cruz, C. S.; Andrade, E. L. P.; Figueiredo, R. M. C. Processo de Contratação de Serviços de Tecnologia da Informação para Organizações Públicas. Secretaria de Política de Informática/ MCT, Brasília, 2011, 212 p.

GiL, A. C. Estudo de Caso: Fundamentação científica, subsídios para coleta e análise de dados, como redigir o relatório. 1. ed. São Paulo: Atlas, 2009. p. 147.

Gondim, Linda M. P.; Lima, Jacob Carlos. A pesquisa como artesanato intelectual: considerações sobre o método e bom senso. São Carlos: EdUFSCar, 2006. 88p.

GuARDA, Graziela Ferreira. Análise de contratos de terceirização de TI na Administração Pública Federal sob a ótica da Instrução Normativa n 4. 2011. 110 f. Dissertação (Mestrado em Engenharia Elétrica)-Universidade de Brasília, Brasília, 2011.

Grembergen, W. V.; De Haes, S. Enterprise Governance of Information Technology. Nova York: Springer Science + Bussiness Media, 2010.

Henkin, H.; Selao, D. C. A contratação de serviços de tecnologia da informação pela administração pública federal. In: CEPIK, M., CAnabarro, D. R. Governança de TI - Transformando a Administração Pública no Brasil. Porto Alegre: WS Editor, 2010. p.75-94.

ITGI, Information Technology Governance Institute. COBIT - Control Objectives for Information and related Technology 4.1. (em português). Rolling Meadows: ITGI, 2007. Disponível em: <http://www.isaca.org/Knowledge-Center/cobit/Pages/Downloads.aspx>. Acesso em: 06.01.2013.

IT Governance and Process Maturity. Rolling Meadows: ITGI, 2008. Disponível em: <http http://www.isaca.org/Knowledge-Center/Research /Documents/ITGov-Process-Maturity-12Nov08-Research.pdf>. Acesso em: 06.02.2013.

IsacA. COBIT 5 Enabling Process. Rolling Meadows, 2012, 230 p.

Malhotra, N. K. Pesquisa de marketing: uma orientação aplicada. 3. ed. Porto Alegre: Bookman, 2001. p. 719.

Software Engineering Institute - SEI. Capability Maturity Model Integration CMMI for Acquisition (CMMI-ACQ), version 1.3, CMU/ SEI-2010-TR-032. Pittsburgh, PA: Software Engineering Institute, Carnegie Mellon University, 2010.

Vergara, S. C. Projetos e relatórios de pesquisa em administração. São Paulo: Atlas, 1998. WeILl, P.; Ross J. W. Governança de Tecnologia da Informação. São Paulo: M. Books do Brasil Editora LTDA, 2006.

Xavier, Maria Betânia Gonçalves. Mensuração da maturidade da governança de TI na administração direta federal brasileira. 2010. 167f. Dissertação (mestrado) - Universidade Católica de Brasilia, Brasília, 2010. 


\section{Resumo - Resumen - Absctract}

\section{Avaliação da percepção da conformidade de processos de contratação de soluções} de Tecnologia da Informação com a Instrução Normativa $n^{\circ}$ 4/2010 da SLTI Diana Leite Nunes dos Santos e João Soura Neto

Este estudo propõe um mecanismo de avaliação da conformidade de um processo de contratação pública de Tecnologia da Informação (TI) com as atividades descritas no guia prático para contratação de soluções de TI baseado na IN - SLTI n 4/2010, em conjunto com uma avaliação da maturidade das fases dessa norma, por meio de um estudo de caso. Os resultados obtidos mostraram que, para o Ministério Público Brasileiro, a conformidade com o normativo alcançou um nível preocupante de aderência, com uma média de $48 \%$. As falhas de conformidade, neste caso, indicam possíveis deficiências na governança e planejamento de TI. A maturidade do processo foi enquadrada no nível 2, que tem foco na repetição de procedimentos, porém de forma intuitiva. Concluiu-se que, para garantir uma maior aderência ao processo, é importante estabelecer controles formais e frequentes, ações de transparência e transferência de conhecimento.

Palavras-Chave: IN 4/2010; Contratações Públicas de TI; Aquisições de TI

Evaluación de la percepción de la conformidad de procesos de contratación de soluciones de Tecnología de la Información con la Instrucción Normativa ${ }^{\circ}$ 4/2010 de la SLTI

Diana Leite Nunes dos Santos y João Souza Neto

Este trabajo propone un mecanismo de evaluación de la conformidad de un proceso de contratación pública de TI con las actividades descritas en la "Guía práctica de contrataciones de soluciones de tecnología de la información", basada en la IN - SLTI 4/2010, así como una evaluación de la madurez de las fases de la presente norma, a través de un estudio de caso. Los resultados mostraron que para el Ministerio Publico brasileño, el cumplimiento de la normativa ha alcanzado un nivel preocupante de adherencia con un promedio de $48 \%$. La falta de conformidad en este caso indica posibles fallos en la gobernanza y la planificación de TI. La madurez del proceso se enmarcó en el nivel 2, que se centra en los procedimientos de repetición, pero intuitivamente. Se concluyó que, para asegurar una mayor adherencia al proceso, es importante establecer controles formales y frecuentes acciones de transparencia y transferencia de conocimientos.

Palabras Clave: IN 4/2010; Contrataciones públicas de TI; Adquisiciones de TI

\section{Assessment of the perception of compliance for information technology procurement process with SLTI's Instruction $n^{\circ} 4 / 2010$ \\ Diana Leite Nunes dos Santos and João Souza Neto}

This study proposes a mechanism for evaluating the compliance of a public IT procurement process with the activities described in the "Practical Guide to contract solutions for Information Technology v 1.1" based on IN - SLTI 4/2010. In this case study it was also performed a maturity assessment of the phases of this standard. The results showed that for the studied Brazilian Public Institution, compliance with the normative reached a low level of adherence with a $48 \%$ average. The poor conformity in this case indicates possible failures in governance and IT planning. The process maturity was framed at level 2 , which means that some processes are repeatable, but intuitive. It was concluded that to ensure greater adherence to process it is important to establish formal controls and frequent actions of transparency and knowledge transfer.

Keywords: IN 4/2010; Public IT procurement; IT acquisitions 
Diana Leite Nunes dos Santos

Mestrado em Gestão do Conhecimento e da Tecnologia da Informação-Universidade Católica de Brasilia (UCB). Contato: diananunes@yahoo.com

João Souza Neto

Doutor em Engenharia Elétrica pela Universidade de Brasília (UnB) e Professor do curso de Mestrado em Gestão do Conhecimento e da Tecnologia da Informação pela Universidade Católica de Brasília (UCB). Contato: sznetoj@gmail.com 